\title{
Social Work and the Environment
}

\section{Thesis}

Presented by:

Manijeh Moghisi, B.S.W., R.S.W.

A thesis submitted to the Faculty of Graduate Studies and Research

In fulfillment of requirements for the degree of

Master of Social Work

School of Social Work

Carleton University

Ottawa, Ontario 
Library and Archives Canada

\section{Published Heritage} Branch

395 Wellington Street Ottawa ON K1A ON4 Canada
Bibliothèque et

Archives Canada

Direction du

Patrimoine de l'édition

395 , rue Wellington

Ottawa ON K1A ON4

Canada
Your file Votre référence

ISBN: 978-0-494-79614-6

Our file Notre référence

ISBN: 978-0-494-79614-6

\section{NOTICE:}

The author has granted a nonexclusive license allowing Library and Archives Canada to reproduce, publish, archive, preserve, conserve, communicate to the public by telecommunication or on the Internet, loan, distribute and sell theses worldwide, for commercial or noncommercial purposes, in microform, paper, electronic and/or any other formats.

The author retains copyright ownership and moral rights in this thesis. Neither the thesis nor substantial extracts from it may be printed or otherwise reproduced without the author's permission.

\section{AVIS:}

L'auteur a accordé une licence non exclusive permettant à la Bibliothèque et Archives Canada de reproduire, publier, archiver, sauvegarder, conserver, transmettre au public par télécommunication ou par l'Internet, prêter, distribuer et vendre des thèses partout dans le monde, à des fins commerciales ou autres, sur support microforme, papier, électronique et/ou autres formats.

L'auteur conserve la propriété du droit d'auteur et des droits moraux qui protège cette thèse. $\mathrm{Ni}$ la thèse ni des extraits substantiels de celle-ci ne doivent être imprimés ou autrement reproduits sans son autorisation.
In compliance with the Canadian Privacy Act some supporting forms may have been removed from this thesis.

While these forms may be included in the document page count, their removal does not represent any loss of content from the thesis.
Conformément à la loi canadienne sur la protection de la vie privée, quelques formulaires secondaires ont été enlevés de cette thèse.

Bien que ces formulaires aient inclus dans la pagination, il n'y aura aucun contenu manquant.

\section{Canadä}




\begin{abstract}
Warnings by scientists indicate that there is a global environmental crisis which is threatening both the future of human civilization and the survival of other species. Despite the urgency of the problems facing the world, humans are slow to take remedial action. This is a qualitative study to explore whether social workers in Kingston, Ontario perceive a relationship between environmental destruction and social work and to assess impact on their social work practice. This thesis is written from the following perspectives: international social work, deep ecology, and ecofeminism. It is an attempt to demonstrate the connections that exist between the social work profession and issues of social environmental justice. In particular, the connection between social work and human rights is explored. Environmental rights are included within the field of human rights. Deep ecology and ecofeminism are then reviewed. This thesis is an attempt to determine the opinions, awareness and understanding of social workers concerning the extent of environmental destruction and its importance to the profession and their personal approach to social work. This qualitative study involved in-depth one-on-one interviews with eight social workers in Kingston and analysis of the data collected.
\end{abstract}




\section{ACKNOWLEDGMENTS}

I am grateful to the many people whose help made the completion of this thesis a reality.

First, I wish to acknowledge my debt to the social workers who, despite juggling fulltime employment and family responsibilities, participated in this study. Without their participation I would not have been able to write this thesis. I salute them.

I am also grateful to my supervisor, Dr. Steven Hick, and to Dr. Shereen Ismael, second reader, for their guidance, dedication to teaching, their spirit of generosity and work ethic. My thanks go to my partner Mahmood Rowghani who has supported me throughout the MSW program by driving me between Kingston and Ottawa. I am also thankful to Ms. Paula Loh for her editorial contributions. 


\section{TABLE OF CONTENTS}

\section{INTRODUCTION}

Social Work and the Environment

The Holistic View

The Relationship Between Environmental Justice \& Social Justice 7

Poverty and the Environment

Environmental Destruction and the Refugee Problem

The Three Generations of Human Rights

Environmental Racism

Towards an Equitable Relationship Between Nature and People

New Perspectives: Deep Ecology and Feminism

Deep Ecology

Ecofeminism

Social Ecology Versus Deep Ecology and Ecofeminism

Self Reflective Statement

METHODOLOGY

Introduction $\quad 40$

Data Collection $\quad 41$

Interview Protocol $\quad 46$

Data Analysis $\quad 47$

$\begin{array}{ll}\text { FINDINGS } & 49\end{array}$

How Social Workers Define Environment 49

Environment as a Context $\quad 50$

Environment as Physical and Social

Environment as Just Physical

Social Workers' Views of the Relation Between their Profession and the Environment. 56

The Relationship Between the Environment and Health 56

The Environment and Advocacy $\quad 62$

Local and Global $\quad 69$

Social Workers' Awareness of Environmental Crisis

Shallow Ecology $\quad 74$

Deep Ecology

Is Awareness of the Environment Important to Social Workers?

Awareness of the Physical Environment

Awareness of Justice and the Environment $\quad 84$

Awareness of Politics and the Environment $\quad 87$

Participants' Proposals for Awareness Raising $\quad 92$

Having Contact with Nature $\quad 93$

Promoting Environmentally-Friendly Practices in Workplaces and Living Spaces 94

Offering Environment-Based Courses in Social Work Schools 96

$\begin{array}{ll}\text { LIMITATIONS } & 98\end{array}$ 
THE IMPLICATIONS OF DEEP ECOLOGY FOR SOCLAL WORK PRACTICE

Research

Direct Practice

Social Policy

105

Community Organizing

105

Social Justice

106

International Solidarity

107

CONCLUSION

110

REFERENCES

114

Appendix A: Letter of Information

125

Appendix B : Letter of Consent 


\section{INTRODUCTION}

Attilius tried to order his thoughts, but it was hard to speak coherently. Still, he tried to convey the power of what he had witnessed when the roof of the mountain lifted off. And the blasting of the summit, he said, was merely the culmination of a host of other phenomena-the sulphur in soil, the pools of noxious gas, the earth tremors, the swelling of land which had severed the matrix of aqueducts, the disappearance of the local springs. All these things were interconnected.

- Robert Harris

This passage from a novel "POMPEII" by Robert Harris describes the destruction of Pompeii, a city in southern Italy, which was completely covered by the ashes of Vesuvius and became a lost city for centuries. In Pompeii, the citizens were spending their day as usual, but there were signs that indicated the upcoming great disaster: the disappearance of local springs, a missing person, the largest river going dry. One person did recognize the upcoming disaster, but when he warned others, they either dismissed him or tried to keep him quiet. This was done to avoid panic and to manipulate information. The disappearance of Pompeii occurred in the first century, but the scenario is still very familiar 2000 years later. If we do not pay attention to the signs of environmental disaster, we or the next generation could end up with as great a disaster as Pompeii.

The global environmental crisis is accelerating despite numerous warnings by scientists and environmentalists. Research shows that the air is polluted, drinking water is contaminated, rivers, lakes, and oceans are polluted, the food that we eat is poisoned, and forests are disappearing at an alarming rate (Berger \& Kelly, 1993; Besthron, 2004, 2003, 2002, 2001; Coates, 2005, 2003; Hoof, 1998; Ife, 2002). Every day, residents of the earth learn through the media of the loss of wilderness, deforestation, global warming, and climate change. "These are warning signals that we live in a world that can end, at least 
as a home for conscious life" (Macy, 2007, p.17). The last 200 years of Western industrial society show that, despite all the progress in science and technology and despite all of the past painful experiences, human beings have not yet learned to live in harmony neither with the natural world nor even among ourselves. The crisis that we are facing is so real and so close that urgent action is needed. These warning signals tell us about "our collective forms of our ignorance, fear, and greed" (Macy, 2007, p. 43).

Many scientists and other experts are warning people that the earth is approaching a state of crisis or is indeed already in an environmental crisis. The International Federation of Social Workers adopted a new definition of social worker at the IFSW General Meeting in Montreal, Canada, July 2000. It defined social workers as an agent of change in society. This international definition of the social work profession replaced the former IFSW definition adopted in 1982. It is understood that social work in the 21 st century is dynamic and evolving, and therefore no definition should be regarded as exhaustive. According to the IFSW, social workers, whose role is to address the barriers, inequalities, and injustice that exist in society, may have an important role in resolving the problems that are causing the crisis. To play this role, social workers and the social work profession will need to re-orient their traditional perspectives and theories. This is what Ife calls linear thinking. (Ife, 2001, p.148). This is based on the past 100 years of Western philosophy which has held that humans are superior to nature and other beings. It has failed to recognize that we are only one part of the complex web of life which is our natural world.

We must create now a new world view and shift to a new paradigm, to a new way of thinking, to a more holistic perspective of our relationship with nature (Besthron, 
2004, 2003, 2002; Coates, 2005, 2003; Hoof, 1998; Ife, 2002; Macy, 2007; Naess, 2001; and Shiva, 2005). Also, social workers need to expand their horizon to a global stage, because in this age of globalization, some of the problems of our clients may be caused by global forces. Now it is time to extend knowledge and action from local to global if it wants to be effective in the 21st century (Healy, 2008; Ife, 2002, 2001).

\section{Social Work and the Environment}

Since its beginning in the past century, social work grew out of humanitarian as well as democratic ideas. The values of social work are based on the dignity, worth, and equality of all people. Its practice is based on meeting human needs, rights and potential. Human rights and social justice are two pillars of the social work profession and values. The emergence of new ideas about how human activity created these environmental disasters are encouraging social workers to expand their understanding of their role in the human community a more holistic perspective. "Social workers will be called upon to consider people and their environment as connected and interdependent and to develop interventions which contribute to a healthy relationship between humankind and its planet" (Coates, 2003, p.10). Advocates of this new approach call for social work education and practice to be more active for social and environmental justice. Social work theory and practice have already undergone considerable change during the past century. The current situation requires further adjustments.

Historically, the profession of social work, which developed "within the dualistic and mechanistic world view of modernity, has made only limited efforts to act on a more holistic conception of the environment" (Coates, 2003, p.38). In its early days, the focus 
of the profession was on the social environment. In the 1960s, the profession was strongly affected by radical political ideas, but "social work has been strongly absent from environmental discourse" (Coates, 2003, p.38). The primary activities of the profession have been to help people to fit and adjust to modern life and cope with the problems of the capitalist system. Even though the profession later reached out to the oppressed population (minority, women, gay and lesbian, disabled people), overall it has been an agent of the system and a "domesticated" (Coates, p.38) profession. In the 1960s, the profession began to question its traditional approach to the environment. Later, general system theory was incorporated into social work "to understand human behavior in more complex and multi-dimensional relationship, instead of focusing exclusively on individual situations" (Coates, 2003, p.42). A pioneer in criticizing social work for not considering broader environmental contexts is Besthron. But, despite some efforts (Besthron, 1997; Ife, 2000; Hoff, 1998; Coates 2003), knowledge in this area is in its beginning stages, and the focus of the profession remains on the person and social environment. There is still no effort to acknowledge the need to introduce environmental concerns into social work education, let alone practice. Coates indicates that:

Despite mounting evidence of negative effects brought about by marketdominated industrialism, pollution, loss of habitat and extinctions, and despite discoveries in evolution that challenge traditional beliefs about the role of humans on earth, mainstream social work has not given serious consideration to the challenge posed by environmental devastation $(2003, \mathrm{p} .45)$.

But there is a connection between ecology and social work: to foster a healthy relationship between people and their environments. Though, in the past, the profession 
failed to consider the physical environment in its picture of society, now that the crisis is reaching its peak, there is no excuse for its negligence and it is time that the profession considers the implication of this crisis. "An adequate social work response to the physical environment will demand a more holistic approach to practice through incorporation of environmental, economic, and political dimensions of society" (Hoff, 1988, p.27). Yet, as Ife argued, moving beyond linear thinking is not an easy task for social workers educated within the Western tradition because this tradition "has consistently emphasized linear casual relationship, following a single line of inquiry, and research that discovers more and more about less and less by studying a small part of the overall picture instead of trying to understand how all the different components interact and contribute to a whole that is greater than the sum of its parts" (Ife, 2001, p.148).

Social work education and practice has been slow to challenge and change this linear way of thinking because they are both based on a philosophy that treats human intelligence as a supremely important force in the world. In this regard, social work is no different from any other field of study or work in West, but change is coming and slowly. In a Manual for Schools of Social Work and the Social Work Profession prepared for the United Nations Centre for Human Rights in 1994, article 62 clearly indicates that degradation of the environmental is not possible to ignore any more.

Environmental degradation is too evident to be ignored. The world economic order, faulty development models, inequality with regard to all resources, nuclear, industrial and other pollution and consumption patterns in industrialized as well as developing countries are recognized as causes of the Earth's serious plight. Excessive consumerism and excessive poverty endanger nature as well as 
vulnerable groups of people through greed, lack of information or need for survival (p.10).

Therefore, we must create a new world view; shift to a new paradigm, to a new way of thinking, to a more holistic perspective of our relationship with nature. (Besthron, 2004, 2003, 2002; Coates, 2005, 2003; Hoof, 1998; Ife, 2002; Macy, 2007; Naess, 2001; Shiva, 2005). Also, social workers need to expand their horizon to a global stage, because in this age of globalization, some of the problems of our clients may be caused by global forces. As Ife argues (2001) "all social work practice, wherever it occurs, must now be regarded as working at the global/local level" (p.13). Now it is time to extend its knowledge and action from local to local and global if it wants to be effective in the $21^{\text {st }}$ century (Healy, 2008; Ife, 2002, 2001).

\section{The Holistic View}

Two sources of a more holistic view in Western culture have been ecofeminism and deep ecology. These views emphasize the interconnectedness of everything as part of an ecological approach and challenge linear thinking about ecological disaster and its consequences (Besthron, 2002; Ife, 2002). These views understand that humans are not at the centre of the universe. Deep ecology and ecofeminism is about our interconnectedness with the earth and all its living entities. It is a philosophy of harmony between humans and nature. It is about seeing ourselves as a part of nature and all its living entities. This holistic world view also exists in non-Western traditions such as Buddhism and Aboriginal cultures. Buddhism emphasizes harmony and balance. Buddhism views humans as an integral part of nature, therefore, if people abuse nature, in 
reality they are abusing themselves. It sees nature as a mother who gives everything to her children with joy. Therefore, there is great respect and gratitude towards nature. (Badiner, 1990; Ife, 2002; Macy, 2007).

Aboriginal views also emphasize oneness with nature and the importance of harmony with nature. In these world views, all things are interrelated. Everything in the universe is part of a single whole and everything is connected in some way to everything else. It is, therefore, possible to understand something only if we can understand its connections to everything else. Adherents to these non-Western traditions believe that human beings need the earth to be healthy for its own sake and for the sake of our own survival. Indigenous peoples around the world understand and experience themselves as intrinsically and spiritually related to the land and all living beings.

The Earth provides us with all that we need. It provides us with food, shelter, water, clothing, companionship. Everything is provided by the Great Mother, the Sacred Woman. Just as she does this for us, so our relationship to her must be reciprocal. That is the whole meaning of our Existence" (Gkisedtanamoogk, 1993, pp.14-15).

In this world view, life is sacred and we need to be thankful for it. The lives of other species and natural things are also treated as sacred.

\section{The Relationship between Environmental Justice \& Social Justice}

The question that arises is this: considering the environmental crisis that is facing the whole world in the beginning of the 21 st century, is it possible to solve these problems without social justice? Is it possible to deal with the environmental crisis and 
not deal with hunger, oppression, violation of human rights, and inequality between the so-called South and North, and men and women? The answer is NO. "Both are necessary and they need to complement each other" (Ife, 2001, p.40). If social workers are seeking a better world that includes both sustainability and equality, they have to integrate both social justice and ecological justice into their perspectives.

The current context of economic globalization, increasing militarization of society and armed conflicts, the retrenchment of the social welfare system and growing social and economic inequality between, and within, countries underscores the importance of an approach to social work practice based on social justice and human rights (Lundy \& Wormer, 2007).

If we accept the concept that the world is one single system and that human beings are just one part of this system, then social justice and environmental justice should be seen in a broader perspective which includes the global perspective.

\section{Poverty and the Environment}

The relationship between poverty and destruction of the environment is very complex. Living in challenging and unpredictable climatic conditions affects poor people's lives and may push them in deeper poverty. Environmental disasters such as fire, flooding, pollution, soil exhaustion, and deforestation are examples of disasters that may push already poor people to extreme poverty or even to migrate to other places (Agarwal, 1996: Borges, 2007; Brocklesb \& Hinshelwood, 2001; Chossudovsky, 1998; Lufumpa, 2005; Shiva, 2005). Poor people in rural areas, who rely on nature and natural resources, are especially vulnerable to environmental change and disaster. It has been 
suggested that in urban areas, the pollution of water and the flooding of housing in poor neighborhoods are both causes and consequences of poverty. Recent examples are the tsunami in Asia in December 2004, and Hurricane Katrina in North America in August 2005. Both of these natural disasters destroyed the lives of poor people and their communities, and pushed them to extreme poverty. In these situations, poor people have to cope with immense loss and rebuild their lives with very few resources. Many have to migrate to other areas, increasing the number of urban poor or refugees in another country.

\section{Environmental Destruction and the Refugee Problem}

The problem of the refugee situation has reached enormous proportions in past years. According to UNHCR's most recent statistics:

Some six million people (excluding the case of more than four million Palestinian refugees) have now been living in exile for five years or longer. The vast majority of them in Africa and Asian countries which are already struggling to meet the needs of their own citizens" (Statement by UN High Commissioner for Refugees, December 2008).

Sometimes, people choose to leave their families, communities, and their countries, for economic, $\mathrm{r}$ personal or political reasons. These decisions, somewhat, are made as a matter of choice. But when there is a natural disaster, there is no choice. Homes are destroyed and sometimes uprooting entire communities.

Historically, refugees have been understood to be people who flee their countries of origin to escape political persecution. But today, it is recognized that refugees include 
people who are displaced by environmental and economic adversities (Mupedziswa, 1998, p.114). There could be 200 million "climate refugees" by 2050 , according to a new policy paper by the International Organization for Migration, depending on the degree of climate change. Even though political persecution is the main reason for refugee movement, environmental factors also cause displacement of people. Natural disasters and man-made disasters have been major causes of displacement. In the Sahel region of Africa and Mozambique, environmental difficulties have created mass refugee movements (Mupedziswa, 1998, p.114). The social impact of climate change has been one of the key themes identified recently by IFSW president David N. Jones. "The social consequences of climate change will have a real impact on us all." Jones has also recently been quoted as saying: "Everyday social work practice will be affected. Social workers already know that the global social movement has a real impact in the homes of people we meet, affecting family relationships and creating social problems. Climate change will affect the very basics of life and peace-water, food, energy, and land." One of the most famous cases of a man-made environmental disaster is the Chernobyl nuclear accident in Russia. The entire city had to be evacuated and abandoned, triggering a mass population movement.

Poverty can exacerbate ethnic tensions because people compete for scarce resources (Gachuruzi, 1996, pp.24-25). As a 1993 UNHCR report noted, the dislocation of the natural resource base, coupled with demographic pressure and chronic poverty, can exacerbate existing political, ethnic and social tensions and force people to flee. The links between poverty and environmental degradation have been demonstrated. Natural disasters, unpredictable climate and seasons, pollution, deforestation, soil exhaustion, and 
erosion are all contributors to poverty around the world (Brocklesb \& Hinshelwood, 2001; Chossudovsky, 1998; Duraiappah, 1998).

\section{The Three Generations of Human Rights}

The social work profession is the one that "promotes change, problem solving in human relationships and the empowerment and liberation of people to enhance well being. Utilizing theories of human behaviour and social systems, social work intervenes at the points where people interact with their environments. Principles of human rights and social justice are fundamental"

- Hare, 2004

Recognition of human rights has evolved over the centuries. Because human rights are violated all over the world, the need for respect for human rights is still one of the most powerful ideas in contemporary discourse (Ife, 2001). Human rights are an important focus for social workers, providing the moral basis for their practice. Article 24 in the Manual for Schools of Social Work and the Social Work Profession clearly states that:

Human rights are inseparable from social work theory, values and ethics, and practice. Rights corresponding to human needs have to be upheld and fostered, and they embody the justification and motivation for social work action. Advocacy of such rights must therefore be an integral part of social work, even if in countries living under authoritarian regimes such advocacy can have serious consequences for the social work profession (p.5).

The International Federation of Social Workers (IFSW) and the International Association of Schools of Social Work (IASSW) clearly consider that those involved in the field of 
social work education and practice have a commitment to the promotion and protection of human rights. Some even call social work a human rights profession (Ife, 2001, p.41). Even though social workers operate in a local culture and society, the language of human rights is a universal discourse based on our common humanity and global citizenship (Ife, 2001). Therefore, the social work profession needs to extend its vision and broaden its application. Social work claims that its goal is social justice in whatever setting. Now is the time to also include the three generations of human rights practice and education. Ife (2001) in his book Human Rights and Social Work: Towards Rights-Based Practice, explains the three generations of human rights in the following way.

Human rights relating to civil and political rights are categorized as first generation. These rights, which are individually based, are essential to an effective and fair society. These rights include the right to vote, the right to freedom of speech, the right to a fair trial and the right to equality before the law, among others. These rights derive from the $18^{\text {th }}$ century period of Enlightenment and are a product of the development of liberal political philosophy.

The second generation of human rights is a collection of rights focusing on economic, social, and cultural rights. The right to employment, the right to an adequate wage, the right to housing, and the right to adequate food and clothing are several examples. Second generation human rights arise from the thinking of the $19^{\text {th }}$ and $20^{\text {th }}$ centuries, and originate from social democracy and socialism.

In contrast to rights applicable to an individual, third generation human rights are defined as rights belonging to a community, population, society, or nation. These rights include the right to economic development, the right to benefit from world trade, and 
environmental rights such as the right to breathe unpolluted air, the right to clean water, and the right to experience "nature." Their origin is more recent and they are recognized as the collective rights of the $20^{\text {th }}$ century. They arise from struggles against colonialism as well as from the struggles of environmental activists. The under-appreciation of third generation rights has been mirrored in Western social work. Due to this devaluing attitude, Western social work does not take communal rights as seriously as individual rights. Some argue that this attitude has led to alienation, loneliness, depression, and loss of community (Ife, 2001). The argument here is not that communal rights are more important than individual rights; both are necessary and need to complement each other.

\section{Environmental Racism}

The world's poor people suffer disproportionately in the social and economic spheres, as well as in the environmental domain. Presentations at the June 1992 United Nations Conference on Environment and Development (the Earth Summit) in Rio de Janeiro emphasized the link between poverty and the destruction of the environment. The point was made that poverty, environmental issues, and population can no longer be dealt with as separate concerns. The relationship between the inability to escape poverty and exposure to toxic waste manifests itself at the national as well as the international level. Poor people in the developing world or so-called "South" and visible minority and poor people living in Western countries are facing a growing number of environmental challenges. The relationship between poverty and the environment is so extensive and complex that it is not possible to capture all of its dimensions in this brief discussion. Therefore, the focus of this thesis is on one aspect of this relationship, namely, the 
exploitation of poor nations as well as low-income minority neighborhoods in Western countries. In this thesis, I will provide a brief explanation of how the international trade in toxic waste has affected people in poor nations and of how low-income, visible minority citizens of Western nations have also been affected by this kind of waste disposal.

Few researchers deny that there are links between local and global environmental struggles. There is also a connection between the struggles of poor and visible minority people in the West and the actions of the emerging international environmental justice movement, whose members fight to address threats resulting from globalization, poverty, militarism, human rights violations, and the toxic waste trade in the South. In both areas of the world, environmental and economic conditions are linked to the activities of global corporations that exploit people, spoil the soil, and create environmental wastelands in both developed and developing countries. However, in developing countries, life is even worse than it is for those in harsh situations in the West because of human rights abuses, lack of adequate infrastructure for sanitation, lack of electricity, and the scarcity of other basic services (Bullard, 2005, 2000, 1993; Camacho, 1998; Coates, 2003; Rogge \& Darkwa, 1996).

The terms "environmental justice," "environmental racism," and "environmental equity" came to public attention during the past two decades (Bullard, 2005, p.1). The vocabulary emerged out of the isolated struggles of small grassroots movements and spread across the globe. "The call for environmental justice can be heard from Chicago's South Side to Johannesburg's Soweto" (Bullard, 2005, p.1). It has been argued that environmental racism is one link in the chain of actions that together make up 
unsustainable development. The violation of human rights and denial of environmental protection and economic opportunities to communities where poor and visible minority people live and work constitute environmental racism. During the past two decades, millions of people around the world, based both in less developed and developed countries, and from many backgrounds, including research, grassroots activism, and community development, have recognized that environmental injustice is an unethical practice that leads to the violation of human rights and civil rights. Activists who work on the front lines of environmental issues and also poor and visible minority people know that environmental injustice is a matter of life and death. In the United States, a 1999 study by the Institute of Medicine of the National Academies concluded that "communities populated by low income groups and people of color are exposed to higher levels of pollution than the rest of the nation, and that these same populations experience certain diseases in greater numbers than more affluent white communities" (Bullard, 2005, p.4).

It has been suggested that this concentration of pollution occurs because less affluent communities and neighborhoods and also less developed nations are not treated as equals of wealthy communities and nations. Some areas become dumping grounds for garbage, hazardous waste, and other toxic materials because, a small number of institutions and individuals exercise political and economical power. These hierarchies are at both the national and international levels. Some writers (Agyeman, 2005; Bullard, $2000 \&$ 2005; Camacho, 1998; Checker, 2005) acknowledge the negative impact of "technological pollution" on communities. This impact occurs as a result of damage to the environment caused by air pollution, contaminated water, and the dumping of toxic 
materials in less affluent neighborhoods. A number of researchers have studied the relationship between racism and the environment. The largest hazardous waste landfill, which receives toxic materials from forty-five states and several foreign countries, is located in predominantly African American and poor counties in the heart of the Alabama Black Belt" (Camacho, 1998, p.66). In Houston, Texas, "six out of eight municipal incinerators are located in principally African American neighborhoods. One of the other two is located in a mainly Latino neighborhood." (Bullard, 2000, p.47).

Before the 1980s, members of visible minority communities had little involvement in issues related to environmental justice. Camacho explains that they could not afford to be concerned about their environments because they were so occupied by the business of day-to-day survival. Another possible reason was that the mainstream environmental movement at that time was composed largely of white middle-class people whose primary concern was to preserve natural areas and protect endangered animals (Bullard, 2000 \& Camacho, 1998).

In 1980, a powerful movement emerged in the U.S., which, by the early 1990 s, guided the federal policy agenda towards greater involvement of various communities in environmental issues. The reason for this shift was that activists noticed that poor Hispanic, Native, and Black Americans were being exposed to more environmental pollution than white, middle-class neighborhoods (Bullard, 2000 \& Camacho, 1998).

This type of racism manifests itself both nationally and internationally. In December 1991, Lawrence Summers, then chief economist of the World Bank, argued the following in an internal memo to colleagues: 
Dirty Industries: Just between you and me, shouldn't the World Bank be encouraging more migration of dirty industries to the LDCs (Less Developed Countries)? I can think of three reasons:

1. The measurements of the costs of health impairing pollution depend on foregone earnings from increased morbidity and mortality. From this point of view a given amount of health impairing pollution should be done in the country with the lowest cost, which will be the country with the lowest wages. I think the economic logic behind dumping a load of toxic waste in the lowest wage country is impeccable and we should face up to that.

He goes on to suggest Africa, for example, would be the best place because "countries in Africa are vastly under polluted; their air quality is probably vastly inefficiently low compared to Los Angles or Mexico City" (www.counterpunch.org/summers.html). In a large number of less developed countries, the majority of the population is nonwhite. The widespread acceptance of this economist's advice would mean that hazardous waste produced in rich, white countries would be dumped in poor, non-white countries. Today's racism is not a simple phenomenon; it has many faces and is hidden behind a variety of masks.

In the unequal relationship that has developed between industrialized and less developed nations, toxic chemicals produced in industrial nations do not remain there because of government regulations and opposition from local groups. Instead, the chemicals are moved and dumped in poor countries. Because institutions in industrialized nations are encountering problems in the disposal of their toxic waste, they are turning to poor countries where people are ill informed about the dangers of toxic waste to their 
health and to the environment. The absence of democracy in many less developed nations makes it difficult for advocacy groups to operate effectively (Bullard, 2000; Camacho, 1998; Rogge \& Darkwa, 1996). Some communities and individuals accept dumping because of their extreme poverty. In 1987 and 1988, a Nigerian man rented his backyard to house 4,000 tons of industrial toxic waste from Italy for just $\$ 100$ a month. The outcome was that the village water supply was contaminated, and 20 villagers died from exposure to the waste (Rogge \& Darkwa, 1996). Poor nations also accept toxic chemicals to reduce their huge national debts. For example, the government of Guinea-Bissau agreed to accept 15 million tons of European toxic waste for compensation of $\$ 120$ million yearly. Later, public opposition forced the government to cancel the agreement (Rogge \& Darkwa, 1996).

Twenty five years ago, thousands of people died from breathing gas from an explosion caused by Union Carbide India Limited (UCIL). Within three days, up to 10,000 people succumbed to their injuries from the gas. Compared to its sister plan in the USA, the Bhopal factory was built in the midst of poor, crowded neighborhoods. It was a disaster waiting to happen. Even now, about 15 people still die from gas-related conditions each month (Amnesty International, 2009, p.11). People in the area suffer from high rates of cancer, respiratory illness, immune disorders, anxiety and depression. The water is contaminated. Those using the contaminated water are especially prone to reproductive problems including late menstrual onset with early menopause, as well as birth defects. No man wants a "Bhopal bride" (Amnesty International, p.11). This case, Bhopal, is one of the most appalling examples of corporate abuse of human rights. 
We do not need to go to developing countries to see these tragedies. The Conservation Council of New Brunswick recently released an exposé that traces a 40year-old trail of government neglect and deceit about the contamination of the community of Belledune. Even though the government knew that the lead contamination posed a health risk to the people of Belledune, it kept those families in the dark for an entire generation (The CCPA, 2006, p.6). For the last five years, Canada's Aamjiwnaang people, who live in the middle of an area (in Southern Ontario) containing 20 percent of Canada's chemical refineries, have given birth to nearly two girls for every boy. Also, women in this small community are suffering higher numbers of miscarriages, and local schools are reporting more learning disabilities among their students. Samples taken from water flowing through the reserve were found to contain PCBs and hexachlorobenzene (The CCPA, 2005, p.17). Polar bears are now ingesting greater quantities of toxins such as PCB waste and mercury, which then get into the Inuit's diet in amounts that can endanger their health, according to David Lean, a biologist at the University of Ottawa (The CCPA, 2005, p.37). Another example is Port Hope, Canada's nuclear wasteland. Port Hope is saturated with toxic heavy metals and chemicals. Millions of cubic meters of radioactive waste spread under homes, schools, parks, and in neighborhoods (The CCPA, 2008, p.39).

Despite the fact that social workers engage in human rights advocacy, members of the social work profession have paid little, if any, attention to the relationships among poverty, toxic waste disposal, and the damage done by such disposal to human health and well-being (Ife, 2001). It has been suggested that given all the information social workers have regarding local and international relationships, it is time for them to fight and 
expose the nations and businesses that abuse people. Social workers in industrialized nations have a moral and professional obligation to cooperate with social workers in poor nations, and also with groups in their own countries, in the effort to educate people regarding environmental threats. Social workers need to work with grassroots groups in less developed countries, for example, Greenpeace and other organizations with global connections, to create strategies for dealing with toxic waste. The knowledge that environmental groups in the West have acquired over the years about how to deal with exposure to toxic materials and contamination can be communicated to these groups (Ife, 2001).

Before this transmission occurs, social workers need first of all to educate themselves regarding the historical relationship between growth and environmental problems. They need to learn more about the relationship between poverty and environmental degradation, and the links between poverty and deforestation, toxic waste disposal, and water shortages. Social workers should also learn more about the connections between poverty and illiteracy, between women's reproductive rights and poverty, and between democracy and environmental problems. National and international organizations of social workers should acknowledge their moral obligations to work more closely with international organizations, such as Greenpeace or Amnesty International, in order to resist inequities in the practice of toxic waste dumping. These inequities also need to be publicly exposed. For these changes to occur, a shift in thinking about the relationships between ecology and social work has to occur among members of the profession (Ife, 2001). 


\section{Towards an Equitable Relationship Between Nature and People}

All these ways of defining the relationships between humans and the environment deal only with the damage done to the welfare of human beings and not with the need to develop an equitable relationship between nature and people. Such concerns do not affect social work practice in a substantial way. Some social work researchers have recently started to pay attention to the environment as an appropriate area of intervention by members of the profession (Besthron, 1997; Ife, 1997; Coates, 2000; Hoff, 1998). These researchers encourage social workers to work with communities and to help mobilize them in efforts to solve their problems. They argue that environmental problems are becoming increasingly evident as a result of the activities of consumer-oriented, marketdominated societies that have enslaved people and detached them from the environment. Societal values, which are based on consumerism and consumption, disconnect humanity from nature.

Environment-oriented researchers point to the need for social workers to take an approach based on respect for the earth and a new model for the relationship of humans and nature. They point out that social workers are uniquely positioned to recognize the deterioration of the environment and the impact of the deterioration on people. Overall, study of the history of social work reveals an anthropocentric approach to nature. An anthropocentric (human-centered) value theory puts only value on human beings and regards all other things, including other forms of life, as being only valuable to the extent that they are means or instruments to serve human beings (Callicott, 1984; Murdy, 1974; Thompson, 1993; Grey, 1993). Leaders of the profession have failed to understand the connection between the well-being of humans and the protection of the environment. 
The above-mentioned writers are beginning to bring awareness of the relationship between a healthy environment and a healthy society to the field of social work.

Social workers are well positioned to engage people in issues of social and environmental justice. Members of the profession can help people to understand how much their well-being is adversely affected by the destruction of the environment. They can also can focus on people's abilities to resist environmental destruction and to secure the well-being of their communities. To do so, first, they have to increase their knowledge about, and appreciation of, the earth and the relationships among species. This change involves a new vision, a new world view, and a full appreciation of the world and all the beings in it. Then, social workers will be able to support communities in their efforts to speak for themselves, to exercise their rights, to achieve environmental justice, for their communities. As Dr. Maathai said in December 2004, when she accepted her Nobel Prize for the environment:

The Norwegian Committee has challenged the world to broaden the understanding of peace: there can be no peace without equitable development; and there can be no development without sustainable management of the environment in a democratic and peaceful space. This shift is an idea whose time has come. 


\section{New Perspectives: Deep Ecology and Ecofeminism}

Even though there are differences in the terminology (i.e. environmental, ecological, light green, dark green, or deep ecology) that is used by various writers (Besthorn, 2003, 2002; Fox, 1989; Ife, 2002; Pepper, 1993; Zimmerman, 1990); overall, there are two distinct schools of thought: environmental and green.

Environmental responses to problems have two characteristics. First, they treat each problem separately and suggest a specific solution to that specific problem. They fail to see the problem in a larger context and in a more holistic way. For example, one of the problems of the environmental crisis today is overpopulation. The solution to this problem, according to environmentalists, is family planning. Even though family planning is crucial to control overpopulation, what is important at the same time is consumption. "Compared to the average citizen of India, the average American uses 50 times more steel, 56 times more energy, 170 times more synthetic rubber, 250 times more motor fuel, and 300 times more plastic" (Jensen, 2004, pp.8-10). According to this writer, although people in the U.S. constitute less than five percent of the world's population, they use more than 25 percent of the world's resources and produce 25 percent of global waste and pollution. Considering consumption, Canadians are as guilty as Americans. According to the Toronto Star, October 20, 2008, 10,000 diapers are used by the average baby before toilet training. More than four million disposable diapers are discarded in Canada per day. An estimated one billion trees a year are required to produce disposable diapers. (p.A6). By the age of six months, the average Canadian has consumed the same amount of resources the average person in the developing world consumes in a life time (p.A6). Each problem is seen in isolation from the whole. This is 
what Ife calls "linear thinking," which has predominated during the past one hundred years of Western civilization and is still the dominant view. The second characteristic of environmental philosophy is the belief that the problems can be solved within existing political, social, and economic system. They do not challenge the existing capitalist order. They have faith in the capitalist system to be able to solve these problems through sophisticated technology if there is enough "will" and "commitment." The problem with the environmentalist argument is the nature of capitalism. It is in its nature to destroy, and its practitioners exploit humans and nature because of their greed. Capitalism does not have any other choice because of its nature. Novelist Jane Smiley wrote:

Given what these big corporations routinely do, we have to ask: are they filled from top to bottom by ruthless monsters who care nothing about others or about the world we live in? Or are they just beyond stupid and blind, so that they, alone among humans, have no understanding of the interconnectedness of all natural systems?" (The CCPA, 2006, pp.12-16)

I would argue that they know what they are doing, but have no choice because of the system. Capitalism is a system of profit and consumption; otherwise it cannot go ahead. It cannot be preoccupied with the loss of nature or loss of human habitat due to rising oceans or global warming. Therefore, from my point of view, faith in this system is simply an illusion.

In contrast, the green school of thought takes a more radical and fundamental approach to these problems. The greens believe that the existing social and political order needs to be changed if we want to solve these problems. They do not see the problem as a separate entity, but as a natural consequence of existing social, political, and economic 
order. Therefore, to solve the problem, we have to see it from a more holistic perspective. These issues are consequences of the type of society we have created. To resolve them, we have to change the existing order. The greens argue that technology is able to deal with the symptoms and not the cause. I should mention that there is a division in green literature about what exactly needs to change. Some greens argue that the problems that exist are the consequence of capitalism. They argue that over- consumption, pollution, and waste are the results of growth and industrialization, and that a lack of responsibility has made our planet unhealthy. They argue that capitalist ideology emphasizes individualism and is exploitative of natural resources. Therefore, the solution is socialism. This idea is represented in eco-socialism (Ife, 2001; Pepper, 1993). Ecosocialism contrasts with eco-anarchism. Eco-anarchists state that the environmental crisis is a result of government control, business, and military forces. These forces alienate humans from nature, therefore, eco-anarchists are against any control and they argue that decisions should be taken by communities, from the bottom and not the top.

Deep ecology is a movement as well as a philosophy. Its emphasis is on lifestyle and decisions as well as on action. As Naess, the founder of deep ecology, said, it is "live and let live" (Drengson \& Inoue, 1995, p.4). Patriarchy is seen as the cause of the ecological crisis by ecofeminism. From this point of view, the patriarchal structures of domination, oppression, and control are the forces that have created a competitive and exploitative society (Shiva, 2005). I agree with those who argue that the ecological crisis is not being solved through the existing social, economic, and political order and that we need radical changes in all aspects of our lives and our belief system. We need a new paradigm regarding our relationship with nature and other species. We also have to 
challenge and change our belief that humans are superior to other species and become able to see ourselves as only one part of the cosmos. At the same time, we cannot and should not be inactive and wait until radical change occurs. We cannot afford to underestimate any other efforts that are taking place. It is true that, for example, recycling, changing to compact fluorescent lights, or other energy-efficient steps are only band-aids to this enormous problem. Still, we cannot afford not to take these small steps and wait instead until radical changes happen. All these small efforts lead to the raising of consciousness.

Hopefully, our way of thinking about the environment and our relationships with other species will change, and we will see ourselves as one part of this web of life; we do not have any special rights or privileges that authorize us to dominate and exploit other aspects of life. As Michael Zimmerman argues in Deep Ecology and Ecofeminism, "only by recognizing that humanity is no more, but also no less, important than all other things on Earth can we learn to dwell on the planet within limits that would allow other species to flourish" (p. 140). We need to believe that a healthy planet creates healthy people and vice versa. The life of the environment is our life. Such a view, as I mentioned, is not new and is present in some Eastern traditions and also in the beliefs of aboriginal peoples. Social work professionals have much to learn from other cultures if they want to go beyond their anthropocentric (human-centered) perceptions. 

domination and exploitation. Deep ecology understands that humans are not at the centre of the universe. Their whole existence depends on other beings as well. "Rather than experiencing humanity as separate from the environment and merely existing in it, humanity must begin to cultivate the insight that they are with the environment" (Besthron, 2002, p.86). Deep ecology is about our interconnectedness with the earth and all its living entities. Instead of seeing nature as "out there", with deep ecology awareness, we see ourselves as part of it.

\section{Ecofeminism}

Ecofeminism, which some believe is "a new term for ancient wisdom" (Mies \& Shiva, 1993, p.13), emerged from the feminist, peace, and ecology movements in the 1970s and 1980s. Participants in protests and other activities used the new word frequently. In 1980, participants in the first ecofeminist conference, titled Women and Life on Earth, explored the links among feminism, militarism, ecology, and various ways of healing.

According to Mies and Shiva (1993), ecofeminism is about "connectedness and wholeness of theory and practice. It asserts the special strength and integrity of every living thing." (p.14). In their view, the root cause of destruction of the environment is capitalist patriarchy or modern civilization. It has been argued that the bases of this civilization are a cosmology and anthropology that make a structural division in reality and oppose the two divided parts to each other in a hierarchical fashion. One part, which is considered superior, moves forward to the detriment of the other. Nature becomes 
subordinate to humanity, woman to man, consumption to production, and the local to the global. There is a failure to see "the other" as simply different; instead, the other is treated as an antagonist that needs to be controlled. These ideas are central to the European project of modernity or progress which has been pursued ever since the Enlightenment. According to this world view, society is a collection of atoms that are energized by competing interests. The ties that support life are neglected, and both biological evolution and social development are seen driven by a continual contention of the stronger with the weaker, i.e. by warfare. This view strictly limits appreciation of the possibilities for enrichment offered by various ways of life and cultures. Instead, differences are perceived as threatening. Efforts to unite the atomized constituents of society lead only to further homogenization and rejection of diversity (Mies \& Shiva, 1993).

The ecofeminist approach states the need for a new cosmology and anthropology that acknowledge that life, including human life, is supported by love, cooperation, and mutual care. In this way, diverse life forms, including their cultural manifestations, can be respected and preserved as the sources of well-being and satisfaction. The project to develop a holistic cosmology and anthropology has to include a notion of freedom that is different from the one usually favored since the Enlightenment. The proposition that humanity can be free and satisfied only through emancipation from nature and control of natural processes by rationality needs to be abandoned (Mies \& Shiva, 1993).

Before the growth of the ecology movement, most feminists favored the postEnlightenment view of freedom. Involvement in ecological issues prompted many activists to question why science and technology, which had long been celebrated as 
liberators, had resulted in widespread destruction of the environment. They began to ask why they had lots of commodities, but lacked basic necessities such as clean air, clean water, nourishing food, peace, and strong communities (Mies \& Shiva, 1993).

When women, who were active in various movements such as the feminist movement, perceived the interdependence of all phenomena, they also discovered the spiritual aspects of life. Within both the capitalist and Marxist systems, the attainment of human fulfillment is depicted as dependent on increases in the production of material goods. Life's spiritual dimensions are denied or ignored (Mies \& Shiva, 1993). The ambiguous term "spirituality" has different meanings for various groups. Spirituality is often seen as a type of religion that is not grounded in the patriarchal, monotheistic traditions of Christianity, Judaism, or Islam. These faiths are seen by many as negative toward both women and nature. Many women have tried to rediscover or create a goddess-based religion that recognizes what may be termed a female principle that resides within everything on earth. Such spirituality respects the life force that may be found in all beings. "The spiritual is the life without which no life can blossom; it is this magic which is contained within everything" (Mies \& Shiva, 1993, p.17). This focus on spirituality is relevant to ecology because spirituality leads to recognition of the sacredness of life and the need to preserve it. Respect for the diversity and vulnerability of nature will keep people from treating nature as a non-living container of raw materials that can be turned into commodities (Mies \& Shiva, 1993). Among some activists "attention was also paid to a spirituality of action, and the ways in which social action in the form of justiceseeking, peace-making, and ecological activism could be considered a spiritual path" (Lysack, 2003, p.12). Ecofeminism as a world view stresses the importance of the basic 
necessities; this view is called a "subsistence perspective." A society that embraces a subsistence perspective can live in peace with nature, other nations, and all men and women because that society's members do not consider exploitation and dominance as essential parts of a good life. Many ecofeminists believe that women are closer to this perspective than men are (Mies \& Shiva, 1993; Lysack, 2003).

Deep ecology and ecofeminism are radical perspectives that have attracted much criticism. Both are sources of more questions than answers. The two perspectives may be seen as having different views about the role of men. Many deep ecologists agree that patriarchal institutions are responsible for both violence against women and against nature, but they believe that putting an end to patriarchy would not necessarily resolve dilemmas related to the natural world.

Concern about environmental issues and new ideas about the role of human beings in nature may inspire social workers to develop a more holistic view of their efforts in human communities. "Social work will be called upon to consider people and their environment as connected and interdependent and to develop interventions which contribute to a healthy relationship between humankind and its planet" (Coates, 2003, p.10). Social workers can learn a great deal from ecofeminism and deep ecology. The severity of the environmental issues facing human communities should convince all professionals to incorporate ecological concerns into their work. This is especially true for social workers, who deal with many people that are negatively affected by environmental problems. It is time for those involved in social work education and practice to be more active for social and environmental justice (Besthron, 2003, 2002; Coates, 2005, 2003; Ife, 2003, 2002). Some social work researchers have recently started 
to pay attention to the environment as an appropriate area of intervention by members of the profession (Besthron, 1997; Ife, 2007; Coates, 2000; Hoff, 1998). These researchers encourage social workers to work with communities and to help mobilize them in efforts to solve their problems. They argue that environmental problems are becoming increasingly evident as a result of the activities of consumer-oriented, market-dominated societies that have enslaved people and detached them from the environment. Societal values which are based on consumerism and consumption disconnect humanity from nature. Environment-oriented researchers point to the need for social workers to take an approach based on respect for the earth and a new model for the relationship of humans and nature. They point out that social workers are uniquely positioned to recognize the deterioration of the environment and the impact of the deterioration on people. Overall, study of the history of social work reveals an anthropocentric (human beings seen as the centre of the world) approach to nature. The profession has failed to understand the connection between the well-being of humans and the protection of the environment. The above-mentioned writers are beginning to bring awareness of the relationship between a healthy environment and a healthy society to the field of social work.

Social workers are well positioned to engage people in issues of social and environmental justice. Members of the profession can help people to understand how much their well-being is adversely affected by the destruction of the environment and also can focus on peoples' abilities to resist environmental destruction and to secure the well-being of their communities. To do so, first they need to acquire knowledge about and appreciation of the earth and the relationships among species. This change involves a new vision, a new world view, and a full appreciation of the world and all the beings in it. 
Then social workers will be able to support people and enable them to achieve environmental justice, and to build a healthy society and community.

\section{Social Ecology versus Deep Ecology and Ecofeminism}

As indicated previously, there are many more debates and questions than answers in relation to Deep Ecology and Ecofeminism. Murray Bookchin, a key theorist of the Social Ecology movement, is one of the most critical analysts of some trends in ecological thought, especially Deep Ecology. Social Ecology doctrine is based on the belief that social relationships are at the root of the environmental crisis. Bookchin argues that oppressive hierarchies and inequality among human beings are the causes of the ways humans deal with nature: "the ways they [people] behave as social beings, men with women, old with young, rich with poor, whites with people of color, First world with Third, elites with "masses," are the roots of how they deal with nature" (Bookchin, 1987, p. 1). According to this doctrine, the entire ecological crisis arises from deepseated social problems. Therefore, ecological problems cannot be understood or resolved unless humanity tackles the roots of social problems.

Bookchin argues that "economic, cultural, and gender conflicts, among many others, lie at the core of the most serious ecological dislocations we face today-apart, to be sure, from those that are produced by natural catastrophes"( Boockchin, 1993, p.2). Social ecologists thus oppose efforts to separate ecological problems from social problems. These ecologists depict social problems as arising from today's market economy, which is structured according to the requirements of cruel competition, trade for profit, industrial expansion, and the identification of progress with corporate self- 
interest (Boockchin, 1993). Their argument is that, if human societies do not consider social problems as the roots of environmental crisis and do not deal with these social problems first, their focus will be on symptoms rather than on causes.

In contrast with the approach of Social Ecology, proponents of Deep Ecology call for a holistic approach, which makes no separation between humanity and nature and also attributes the crisis to the damage caused by anthropocentric (human-centered) attitudes. The social ecologists' challenge to Deep Ecology, is, in my view, very harsh; Deep Ecology has been dismissed as " $a$ vague, formless, often self-contradictory, and invertebrate thing called deep ecology" (Bookchin, 1987, p. 3). In his 1987 article, Social Ecology versus Deep Ecology: A Challenge for the Ecology Movement, Bookchin argues that Deep Ecology theorists have no understanding that the roots of all ecological problems can be discovered in society and in social problems. He claims that Deep Ecologists use the word "humanity" in a vague sense and are not able to see the inequality among members of this humanity, that is, "as though people of color were equitable with whites, women with men, the Third world with the First, the poor with rich, and the exploited with their exploiters" (p.3). Bookchin claims that Deep Ecology offers no explanation of the emergence of hierarchies within societies, of the development of classes from those hierarchies, of the foundation of states on the basis of those classes, and of the social domination of women by men, of the poor by the rich, and, ultimately, of nature by humanity.

Social ecologists also disagree with those who claim that destruction of the environment is a result of the activities of modern society and of technologies, and argue instead that 
much of the devastation had already occurred before the advent of industrial society through the use of "simple axes, black-powder muskets, horse-driven wagons, and mouldboard plows" (Bookchin, 1995, p.34).

Although I agree with the belief of Social Ecology that humanity must deal with social problems such as poverty, exploitation, and inequality between men and women, among various nations, and so on, I believe that Bookchin goes too far in his criticism when he calls Deep Ecology "an ideological toxic dump" and uses insulting terms such as "Eco-la-la." This language is the source of my negative attitude towards Murray Bookchin. I would also argue that environmental problems include human dimensions such as poverty, unemployment, health impairments, and displacement, which affect people's lives and can push them to destitution. Social and financial problems as well as health problems may arise from displacement. As a supporter of deep ecology, I would argue that there is no guarantee that a society that does not practice domination and is relatively egalitarian will not exploit the natural world and destroy its biodiversity unless members of society are aware of their connections to nature and respect the natural world.

Feminists and ecofeminists agree on one point, that is, that women have been subordinated throughout the history of human beings. Ecofeminists argue that this inferiority has not been a result of biology but instead of the hierarchy that men have developed. One of the critics of ecofeminism is Janet Biehl, an eco- socialist who was a friend and supporter of Murray Bookchin. She argues that ecofeminism "has not drawn on the best of previous social theory, but instead works in a realm outside it, associated with a mystified notion of 'nature', it largely ignores or rejects legacies of democracy, of 
reason, and the project of scientifically understanding much of natural world as part of a radical libratory movement" (Biehl, 1991, p. 1). Biehl criticizes ecofeminism for what she calls its "irrationalism," its "glorification of early Neolithic" society, and its emphasis on myths and metaphors (p. 2). She argues that ecofeminists build their movement on metaphors and that they do not have any coherent theory.

Biehl also argues that when ecofeminists base their approach on the "nature" of women and on women's biological makeup, which they see as caring and nurturing, they are embracing the male stereotypes regarding women's character and biology. She also questions ecofeminists' theory about the origin of hierarchy (p.41) and asserts that, in their analysis, they examine parts instead of wholes (p. 83).

In recent history, various theories that affirm the importance of persons and of the environment have developed. Each theory has taken a distinctive approach and has emphasized specific applications. Each has attempted to conceive the world in holistic and ecologically sound terms. These theories suggest the need for fundamental changes in human beings' understanding of nature and their relationship with it. The theories all emphasize the importance of compassion and caring instead of domination and exploitation. I believe that, whatever differences there are among various ecologyoriented theorists, the most important question they have to ask and answer is this: how can human beings work together to build an ecology-oriented society and to change the commonly accepted vision? Murray Bookchin calls this vision"anti-ecological." I also believe all these theoretical tendencies have something to offer and that insights can be discovered in each of them. In reality, there are many paths to a deep ecological consciousness and to an ecology-oriented society. Each approach has insights to 
contribute and offer on this journey. In fact, no one has all the answers or a set of final answers and solutions.

\section{Self Reflective Statement}

The Earth is giving us all forms of signals and warnings of its distress. But it seems we are purposely deaf or pretending that we do not see and everything is going to be okay. The mother earth clearly and loudly is telling us that she cannot take any more assault and abuse by humans. We humans are not only infecting the Earth and other species, but also creating suffrage for ourselves and the generations to come.

Throughout this thesis I reported that the air is polluted, drinking water is not any safer to drink as rivers, lakes, and oceans have become dumping places of agricultural, industrial, and human swages, the food that we put in our mouths is poisoned, and finally that forests are disappearing in an alarming rate. Every day, through media, we learn about another assault on earth and on her habitants; human and non-human, and we still lead the same life as though nothing has happened.

From an early age, through the eyes of our parents, we view the nature as something scary, savage, dark, and dangerous. We try to overcome our fear of nature and our anxiety towards it by controlling and abusing it. I think it is the same feeling that an abused man has towards his partner. Abuse of nature is the result of a split in the psyche which cuts us off from the physical world and the philosophy that man is superior to nature and has the right to control it. The "self" is perceived as something different or separated from the universe. The tension between humans and nature grows and becomes more aggressive over the centuries. This new "self" is in constant war with the other 
"selves" and with the nature. I call it new self because as I indicated before in Native American and Buddhist philosophy, "self" is a cosmic being which coexists in the universe.

If we want to prevent the catastrophe that is going to happen sooner or later, we have to redefine our relationship with nature as well as with non humans. We have to look at our arrogance towards each other and towards nature as a whole. We have to come to a new vision that we are not separated or isolated from this universe, but one small part of the web of life. We have to come to this understanding that everything in this universe is dependent on and connected to each other and we are a small part of what is called universe. Hence we are neither superior than a community of aunts in a very remote part of Amazon nor more intelligent than a community of orphan elephants in Kenya.

For this new vision to happen there is work to be done. We have to ask ourselves what kind of world we want to pass down to those who come after us. We have to ask ourselves why we create suffering for ourselves and others; humans and non-humans. Isn't an economy which is based on greed, exploitation, waste, weapons, and abuse of others and nature a collective suicide? Can we respond to our needs (considering what we need is different from what we want), without destroying our world and all its beauties? Can we be indifferent to the pain and suffering of other humans or non-humans, wherever they are, or do we do anything to prevent their suffering? We also have to ask ourselves which one is more beautiful; diversity, human and nonhuman, or homorganic, which is boring from my point of view. 
I have to confess that in the past my attitude was different until I saw a picture of an orphan fawn, adopted and looked after by a woman near Jodhpur in India. At the mud dwelling, the fawn plays with her children and when hungry, the woman breastfeeds the fawn and her own child simultaneously. This picture is an affirmation of the connection between human and nature. For this woman the fawn is not separated, something "there" or "other" but rather a part of her "self". Through the power of her caring, she experiences life in fullness. She is not alienated from nature, but a part of it. She has a profound interconnectedness with life and all its beauty. Only in this way we are able to bring healing to our beautiful world. 


\section{METHODOLOGY}

\section{Introduction}

To my knowledge, there has not been any research done to document this new vision among social workers. The overall objective of this research project is to determine the opinions, awareness and understanding of social workers concerning the extent of environmental destruction and its importance to the profession and their personal approach to social work. Due to the lack of available empirical evidence, this research project is an exploratory study.

The research was conducted using thematic analysis within a qualitative approach. The reason for choosing a qualitative approach was the need to obtain an indepth understanding of the perspectives and insights of the social workers who participated in this research. As Braun and Clarke believe, qualitative approaches are incredibly diverse and complex. Thematic analysis is considered "a foundational method for qualitative analysis" (Braun \& Clarke, 2006, p.78). It is recommended as being the first analytical method that researchers should learn as it provides core skills which are useful for conducting other forms of qualitative analysis. Braun and Clarke have summarized the advantages of the aforementioned method as follows:

- Flexible, as it allows researchers to say broad things about the data to be analyzed;

- Relatively easy and quick to learn and to do;

- Accessible to researchers with little or no experience in qualitative research;

- Results are generally accessible to an educated general public; 
- Useful method for working within a participatory research paradigm, with participants as collaborators;

- Can usefully summarize key features of a large body of data, and/or offer a "thick description" of the data set;

- Can highlight similarities and differences across the data set;

- Can generate unanticipated insights;

- Allows for social, as well as psychological, interpretations of data; and

- Can be useful for producing qualitative analysis suitable for further research.

Thematic analysis is described as "a method for identifying, analyzing and reporting patterns (themes) within data" (Braun \& Clarke, 2006, p. 79). It also allows researchers to organize and describe data sets. In addition, it can be used to interpret various aspects of the research topic.

\section{Data Collection}

The participants of this research were eight social workers working in various organizations in Kingston. The data was collected through one-on-one interviews. Due to the research project's time frame, I selected participants from the Kingston area. I could not chose interviewees from a "list" of social workers due to ethical issues. Therefore, I used the traditional "snowball" sampling method. By using this method, the social workers interviewed were from various agencies and organizations. This maximized the diversity of participants which merits an explanation as follows:

Two of the interviewees had their BSWs, and six of them had their MSWs. Six of them were female and two were male. Seven out of the eight were Canadian-born with 
English as a first language, and the eighth one was an ethnic and visible minority. Three people worked in two different hospitals, another two workers in a mental health institution, and the remaining three worked with immigrants.

$\mathrm{KGH}$ (Kingston General Hospital) is one of the hospitals in which two of the interviewees worked. The role of this health care facility is explained in the following account and demonstrates the environment in which the interviewees worked:

Kingston General Hospital is an acute care teaching facility, with a strong research base, providing inpatient and ambulatory care to the Kingston community and the region, and is the principal teaching hospital for Queen's University. Kingston General Hospital is also the host hospital for the Cancer Centre of Southeastern Ontario at Kingston General Hospital (www.kgh.on.ca/about/about_mission.asp).

Each year, $\mathrm{KGH}$ serves more than half a million people in southeastern Ontario and is the community hospital for the Kingston area. In addition, "it features a robust research program and provides hands-on skill training for 1,900 health care students annually."

Hotel Dieu Hospital is another health care institution in the area which has many social workers serving patients. One of the interviewees worked in this facility. According to the website of this hospital,

Hotel Dieu Hospital is the ambulatory care teaching hospital for Kingston and Southeastern Ontario, providing expert care to more than 500,000 people in the region. Our specialized services include outpatient pediatrics, ophthalmology, diabetes education, breast assessment, day surgery, urgent care and mental health programs. Affiliated with Queen's University, we are partners within 
Kingston's university hospitals, delivering quality health care, leading innovative research and training the health care professionals of tomorrow (www.hoteldieu.com).

Two of the interviewees worked for the Canadian Mental Health Association (CMHA).This nationwide institution, which was founded in 1918, is one of the oldest voluntary organizations in Canada. Each year, it provides direct service to more than 100,000 Canadians through the combined efforts of more than 10,000 volunteers and staff across Canada in over 135 communities. It promotes the mental health of all and supports the resilience and recovery of people experiencing mental illness. The CMHA accomplishes this mission through advocacy, education, research, and service.

The CMHA's programs assist with employment, housing, early intervention for youth, peer support, recreation services for people with mental illness, stress reduction workshops and public education campaigns for the community. In addition, the CMHA acts as a social advocate to encourage public action and commitment to strengthening community mental health services and legislation and policies affecting services. All our mental health projects are based on principles of empowerment, peer and family support, participation in decisionmaking, citizenship, and inclusion in community life (www.cmha.ca/bins/content_page.asp?cid=7\&lang=1))

Three of the interviewees work for the ISKA (Immigrant Services Kingston and Area). This non-profit organization helps newcomers and immigrants settle in the area by providing them with information about language courses, education institutions, health and employment. According to their website: "ISKA offers exciting group sessions to 
help you learn about your new community and make some new friends. Sometimes we have guest speakers come to talk about special programs and services. We encourage our participants to tell us what is of interest to them and how we can make these sessions useful." (www.immigrantserviceskingston.ca). Another interesting initiative taken by the above organization is to organize female and male networking groups which can discuss settlement issues and find solutions for their problems with the help of social workers.

The diversity of the institutions and organizations that the interviewees worked in has allowed me to experience a variety of opinions in response to the general project questions concerning the destruction of the environment. As previously mentioned, the process of data collection for this project was based on face-to-face in-depth interviews. The interviews focused on the following general questions:

1-To understand the definition of the environment among social workers;

2-To identify social workers' understanding of the relationship between their profession and the environment;

3-To assess social workers' depth of understanding as to whether there is an environmental crisis or not;

4-To assess whether awareness of the condition of the environment is important to social workers at the personal and professional level;

5-To identify suggestions by participants about raising the awareness of social workers with regard to environmental conditions.

Based on the above general questions, which represent the objective of the project, the following questions were discussed with the participants.

- What does the environment mean to you? 
- Do you think that there is any relationship between the environment and the social workers' profession? Please explain.

- In your daily work, do you see signs that the current condition of the environment is affecting the lives of your clients? If the answer is yes, in what way?

- Do you think that social workers have a responsibility to learn about the environment in their daily work?

- If the answer is yes, is this responsibility at the local, national or international level?

- In your opinion, does poverty have anything to do with the environment?

- Do you think that people have a right to clean water, air, and food or do you believe that these issues are not in the scope of social workers' responsibilities?

- What is your assessment of the current condition of the environment?

- What are the effects of the current condition of the environment on your clients' daily lives?

- Are there any economic, social or political consequences because of the current condition of the environment?

- In your opinion, is there any relationship between social justice and environmental justice? Please explain.

- What does the term "environmental rights" mean to you?

- Have you heard about "Deep Ecology" or "Ecofeminism"? What do you know about them?

- How would you balance environmental protection with other rights such as development?

- Do you think that social workers need to develop their understanding of global issues?

- Do you think that social workers have an advocacy role in promoting environmental issues?

- In your opinion, which statement makes more sense to you: "think and act locally," or "think and act locally and globally."

- If, in your opinion, the environment is facing any problems, what is the responsibility of the developing countries' citizens? Please explain. 
- Do you think social workers have a responsibility to learn about the changing condition of the environmental and its affect on humans?

- Do you think social workers need to know about the physical environment of their clients or is their social environment enough for our assessment of their problems?

- In your opinion, do we have any responsibilities towards future generations? Please explain.

- Do you think social workers have a responsibility to learn about the current condition of the environment and its effects on human life? Please explain.

- Are there steps we can take to bring a deeper environmental awareness to our work and our profession?

- Can you think of ways to encourage social work schools or other social work institutions to offer courses or workshops on environmental themes?

- Do social workers need to discuss approaches to environmental issues among themselves? If so, what would be the most appropriate forum for that discussion?

\section{Interview Protocol}

Before meeting with the interviewees, they were provided with the list of questions as a basis for discussion. The interviews were "free-flowing conversation" (Madill \& Gough, 2008) to provoke a friendly environment for discussion and to elicit their opinions on the topic. The only way to generate rich data is for the individuals to feel comfortable and safe in a friendly environment, and to be able to engage fully in discussions. One-on-one interviews provided information about the topic and feelings that individuals may have about it. The individuals were informed in advance that the interview would last approximately one hour.

The location of the interview was their choice. It was in their home, office, or a public place. Interviews were recorded and transcribed. All interviewees signed consent forms that were approved by the Ethics Committee. All interviewees were informed that 
they may terminate the interview at any time. They were also informed that I would not use any names in my final report. They were assured of complete confidentiality. Recording the interviews, taking notes during the interviews, and taking notes immediately after the interviews were ways of collecting information and the basis of the data.

\section{Data Analysis}

As mentioned before, in this research, the thematic analysis method was used to extract and analyze data. The first step was to transcribe data from the tape recorders into written form. This process can be seen as time consuming and frustrating but is an excellent way for the researcher to become familiar with the data. Some researchers even argue that "it should be seen as a key phase of data analysis within interpretative qualitative methodology" (Braun \& Clarke, 2006, p.87). It is important that the transcripts contain the information needed for the analysis and that they are true.

The second step was to generate initial codes. Before that, I had already familiarized myself with the data and generated the initial list of ideas regarding the answers to the general project questions. This allowed me to produce initial codes from the data. Codes "identify a feature of the data (semantic content or latent) that appear interesting to the analyst, and refer to the most basic segment or element of the raw information that can be assessed in a meaningful way regarding the phenomenon" (Braun \& Clarke, 2006, p.88). The process of coding allows researchers to start analyzing data as they organize data into meaningful groups. However, coded data differs from units of analysis (themes), which are often broader. There are a number of ways to code 
extracts of data. If it is done manually, we can code our data by writing notes on the texts we are analyzing, or highlight them. "It is important to make sure that all actual data extracts are coded and then collated together within each code" (Braun \& Clarke, 2006, p.89).

The third step was the process of searching for themes. It began when all the data had been coded and collated and I had a list of different codes. This step "involves sorting the different codes into potential themes, and collating all the relevant coded extracts within the identified themes" (Braun \& Clarke, 2006, p.89). In reality, in this step we start analyzing our codes and consider how different codes can combine to form a theme. It is useful to mention that some initial codes can form the main themes and others may form sub-themes and the rest may be ignored.

The fourth step began when I had a set of candidate themes, and it involved the refinement of those themes. In this step, it may become evident that some candidate themes are not valid themes because there is not enough data to support them or the data is too diverse. Other themes may need to be broken down or combined to form new themes (Braun \& Clarke, 2006, p.91). This step involves two levels of reviewing and refining. Level one involves ensuring that all collated extracts will form a coherent pattern. If it appears that coherent patterns can be formed with the extracted data, we can move to the second level. If not, themes or extracted data need to be worked upon.

In the second level, the validity of individual themes is assessed in relation to the general project questions.

The fifth step began when I had a satisfactory thematic that could provide answers to the general questions and may also contain sub-themes. The sixth step, or 
final step, involved writing the thematic analysis which had to convince the reader of the merit of the analysis. "It is important that the analysis (the writing of it, including data extracts) provides a concise, coherent, logical, non repetitive and interesting account of the story the data tells - within and across themes" (Braun \& Clarke, 2006, p.93).

The following report represents the final themes. These themes address the initial research questions.

\section{FINDINGS}

\section{Participating Social Workers' Awareness of the Term "the Environment," the Extent of Environmental Destruction, if any, and its Importance to the Profession}

Here I identify and categorize the different views in which interviewees defined the term "the environment", their understanding of the relationship between their profession and the environment, their depth of understanding as to whether there is an environmental crisis or not, whether awareness of the condition of the environment is important to them at the personal as well as professional level, and their suggestions about raising the awareness of social workers in this matter. Analysis of the interviewees suggests an array of definitions, understanding, and suggestions. The findings below directly address the initial research objectives.

\section{How Social Workers Define Environment}

Analysis indicates the following three definitions of the term environment:

Environment as a context

Environment as physical and social

Environment as just physical 


\section{Environment as a Context}

The social work profession has included the concept of the person/environment in their practice for decades. However, this person/environment has been narrowing defined as it excluded natural environment in this definition. But, as we see, in this category, the interviewees defined the environment in a context, which could be social, physical, and even cultural. Here a social worker claims,

It can be the physical environment of the world, the ecological cycle of sun and rain and earth and life and death. It's also the cultural context so the cultural environment, the language, the culture. [It] can also be socioeconomic status, history. So the context in which something is growing.

Here, the interviewee does not alienate and separate herself from the natural environment.

She is able to expand her definition to also include the natural environment. If we accept that there is an environmental crisis, such a holistic view can provide a basis for solving this crisis, as Coates indicates: "Social work will be called upon to consider people and their environment as connected and interdependent to develop interventions which contribute to a healthy relationship between humankind and its planet" $(2003, \mathrm{p} .10)$.

Another social worker defines it this way: "I guess the first word that comes to my mind is awareness that the environment is a context, like physical, temperamental, and social." This social worker breaks the boundaries of the definition of environment and also includes the physical environment in her definition. She is able to understand that we are not separated nor above nature, but that we are part of it. When we come to this understanding then we are able to cherish it and not destroy it. As Joanna Macy put it beautifully in this statement, "We are not doomed to destroy it by the cravings of the 
separate ego and the technologies it fashioned. We can wake up to who we really are, allow the rivers to flow clean once more, and the trees to grow green along their banks" (2007, p.29).

Another interviewee defines it as follows:

I do think of it very broadly of maybe the context in which we operate. So I know, or guess, we speak mostly from maybe a biological environment but I also think in terms of work environment. We have a community that we live in so that would be social context; that's my environment. I have a physical, ecological context in which we exist that is our environment. I guess I think of it very broadly.

In these examples, the interviewees do not alienate themselves from the natural environment. According to Boxthorn (2002, p.55), the social workers taking this perspective are not alienating themselves but rather connect with physical selves as the source of their imaginative capacities for experiencing the good, the true, and the beautiful.

Within traditional social work education and practice, when we talk about the environment we quickly think about social environment. It is not surprising to think in this way since historically the social work profession borrowed the knowledge base from other sources such as psychology, sociology, physiology, political science and so on. This was done, in part, to elevate the status of social work to a scientific discipline. By following these disciplines, we lost the connection between humans and their physical environment. 
From this perspective, the environment is viewed as multi-dimensional (Besthron, 2002), which comprises social as well as physical and even cultural: "maturing involves a process of widening one's sense of self and identifying with others-family, friends, communities, our own species, and then all species of non-human life" (Besthron, 2002, p.61). Social work theory and practice has been structured in ways that support the dominant vision of people and their social environment. It is time to break the boundaries of the definition of environment and to also include the physical environment in our theory and practice even though it is hard to shift our way of thinking. But, as we see, social workers already are aware of this importance and are including the physical environment in their definition.

\section{Environment as Physical and Social}

At first, this theme seems similar to the first one but there are differences in terms of the environment as physical and social. In this view, social workers were able to see the connection which exists between social as well as physical; in other words, the interconnectedness of the two. In this view, the environment is seen as a whole in which people live: "The world around me, my home, nature and the whole planet, my family, my work environment." Here, the social workers indicate in their definition that the world is not limited to human beings but to the fact that the entire universe is connected. Macy (2007, p.23), a noted deep ecologist, puts it this way: "From the curve of the cosmos to spinning of atoms, the universe engages in a dance of mutual allurement." What Macy is saying is a call for us to wake up to a deeper and caring understanding about our relationship with the Earth or risk its destruction. We need to cherish our 
interconnectedness with great wisdom and profound compassion. Another social worker states: "Well, it can be the physical environment of the world, the ecological cycle of sun and rain and earth and life and death or it could be my family, my community." Another said: "From a social worker perspective or even from my personal perspective it probably means the natural world. So the air, nature. Also it means my family, friends, and my social environment." One defines it as: "It means the world that I live in, outdoors as well as social environment." Yet another interviewee defines it this way: "For me it is physical as well as social. My family, friends, work, community, and nature. I mean the physical environment."

Although what social workers are saying does not directly display the ecological self, but indicates the growing awareness of ecological self. These responses from some of the interviewed social workers are leading to a new sense of self; the one that Besthron calls "an ecological self" (2002, p.53) and Macy calls "the greening of the self" (Macy, p.148). This new self identifies him/herself with nature and non-human beings. This new self is the result of radical environmental philosophy such as ecological feminism and deep ecology (Besthron, 2002). The ecological self emerged from challenging the notion of "human beings as the beginning and end of all natural ecosystems" (Besthron, 2002, p.54). This anthropocentric view (the environment is just a place for humans to explore) goes back to the classic Greeks (Besthron, 2002; Coates, 2003). As Coates argues, "The physical environment remains a source for humans to use and use as a sink for waste products" (Coates, 2003, p.51). This alienation from nature affects the way that we define ourselves as human beings. We see ourselves as separate individuals who master our destinies and have the right to do whatever it takes to achieve our goals with no 
regard to the consequences for others and nature. Unfortunately, as a result of this philosophy, our environment has reached its point of crisis and has forced us to redefine the modern idea of self. The new ecological self considers him/herself as a part of the circle of life which is so interconnected.

Over the past years, some social work scholars and writers have tried to envisage a theory and practice of social work education that enables us to see ourselves and our clients as a part of the whole environment (Besthron, 2001, 2002, 2003, 2004; Coates, 2003, 2005; Germain, 1979; Hoof, 1998, 1996). This will potentially provide greater healing for those who are seeking our help. It seems that some of the interviewed social workers are trying to respond to this call.

\section{Environment as Just Physical}

For some of the interviewees the term "environment" means the physical environment: "It means the world that I live in, and in particular the outdoors." Another social worker defines it in the same way: "The environment means the created world around us, the air, the water, earth, natural created world. We live in the environment and our lives are intertwined within it." Another view is that, "from my personal perspective it probably means the natural world. So the air, nature, and the air we breathe. Something that's more earth oriented." Another defines it as: "The nature. Air, plants, animals"

In this theme, the perspective is only the physical environment. The interviewees understand the human connection to the environment and have appreciation for it. The positive attitude that "we live in the environment and our lives are intertwined with it" 
reflects the growing environmental awareness of people because of rapidly expanding environmental problems that affect our lives. People are more informed by media and by environmentalists as to how nature, as a result of our culture of consumerism and selfishness, fell to its knees. Therefore, we have more understanding and appreciation for it: "fortunately an alternative set of beliefs and values, a different world view, or paradigm, is emerging which seeks to bring about a harmonious and mutually enhancing human/Earth relationship" (Coates, 2003, p.2).

As described in this section, a variety of definitions regarding the term "the environment" has emerged. It is important to be aware of the variety of definitions and the meaning of the term "environment" among social workers; when social workers are talking about the environment they may be talking about different things. As we see, there is a way of thinking about just the physical environment, as opposed to the more holistic view, social, physical and even cultural views. This perspective does not separate humans from nature but sees the environment as a complex interaction between the two. This is because of the importance of environment to society. As Steven Hick and Richard Pozzuto indicated in Social Work a Critical Turn (p.xvii) "there has been a turn or shift in society that has important implications for social worker theory and practice." This finding would suggest that the social worker's notion of the environment has been improved and they are able to include the physical environment into their concerns and their vision even if it is a shallow environment. 


\section{Social Workers' Views of the Relation Between their Profession and the Environment}

The purpose of this section is to determine connects made, if any, that social workers make between their profession and the environment. Analysis indicates three themes in interviewees' responses:

The Relationship between the Environment and Health

Environment and Advocacy

Local and Global

\section{The Relationship between the Environment and Health}

More and more people are beginning to recognize that a healthy environment is vital to their well-being. Our health is affected in different ways by the environment. The air we breathe and the water and food that we consume are becoming polluted which will affect our health gradually and steadily. We are all at risk. Pollution has no boundaries. It affects poor and wealthy, even though more poor people will be affected. It affects young and old, even though children, because of their weak immune system, are more vulnerable. It affects white or black, even though black people are more affected because of their socio-economic status. It affects developed and developing countries, even though developing countries are more vulnerable. The best example is the Chernobyl nuclear disaster, which affected all of Europe. It is one of the environmental degradations that go beyond the boundaries of nations. A growing body of research indicates the relationship between damage to the health of the environment and damage to the physical, mental, and emotional health of people (Clarkson, 1993; Canadian Public Health Association, 1992; World Health Organization, 2000; McMichael, 1993; 
Besthron, 1997 \& 2002; Donohoe, 2003; Coates, 2003; Hoff \& McNutt, 1994; Berger, 1995; Weiss \& Bellinger, 2006; Ife, 2007; Save the Children, 2009).

"I think there is a relationship between the environment and health. Physical environment I mean in terms of chemicals they work around. Physical environment of working shift work, working nights and days, and nights. Living in a toxic city." This interviewee is aware of the relationship between the destruction of the environment and health problems. Researchers at Stanford University in California studied the relationship between climate change and carbon dioxide inhaled by humans. "Ultimately, you inhale a greater abundance of deleterious chemicals due to carbon dioxide and climate change associated with it" (The CCPA, 2008). The same scientists predicted that each degree of global temperature rise in this century could lead to 20,000 deaths worldwide as a result of air pollution. Another comment is that, "I have worked with women who suffer or survived breast cancer a lot of times [who] are trying to understand why there is so much cancer these days. Some times people talk about the food they eat [and] if it is safe." Environmental destruction is now acknowledged as a risk to the health of people. Another interviewee states:

Definitely there is a relationship between health and our environment. I think it is the interrelationship of ourselves and our context in which we live... I work in a health care setting. Many of the children that come here have the poor environment affect their health, certainly. Even just air quality on smog days. We have a lot of medically complex children here and they have to be extra careful in those sorts of situations because it has a huge impact on their health. It can result in them being in the hospital. You hear so much in the media about deteriorating 
health in children and cardiovascular disease. All of those things you just compound in children who have other special needs.

A bulletin of the World Health Organization in 2000 indicates that indoor air pollution in developing countries is a major environmental and public health challenge. This problem increases the risk of chronic obstructive pulmonary disease and of acute respiratory infection in childhood, the most important cause of death among children under age five in developing countries (p.2). The Canadian Public Health Association estimated that 14 million children under five years old die in the world as a result of poor sanitation, tainted water, and environmental pollution each year (Save the Children, 2009; Rogge, 1994). Diarrhea and acute respiratory infection (of which some is related to air pollution) is the cause of death for four million children around the world (p.2). In addition, radiation, mercury, and pesticides also are causes of death among humans. Social workers who participated in this research study were able to identify this relationship based on their day-to-day working experiences. One interviewee explained the effects of the environment on mental health:

A number of people I've worked with have been affected by the environment in which they live; e.g. poor housing, ugly environment outside their windows that disconnects them from the earth and beauty of the natural world. I definitely think this impact their mood. Seeing more clients with health issues: asthma breathing problems, MS, cancer. And I think pollution in our environment is a factor.

Social researchers have documented the effect of degradation of the physical environment on mental illness and social functioning. (Hoof \& Polac, 1993, p.206). If we look back to the founders of the social work profession, such as Jane Addams and 
Florence Kelly, we realize that they recognized the degraded urban environment and human health. Carel Germain was the first social worker who discussed the treatment of the individual and the problem, both in and as part of the environment, instead of focusing solely on the person or the illness as the problem (Rotabi, 2007, p.120). Germain indicates in her article in 1978, Space: An Ecological Variable in Social Work Practice that "human beings have tended to overlook the physical setting in which they are embedded as sources of influence in Behavior" (Rotabi, 2007, p.120). She argues that there are reciprocal interactions and relations between human behavior and nature as well as their social environment. Germain developed the social work ecological theory and contributed to our understanding of the relationship between the social physical environment and people's behavior. Ecological theory recognizes the interconnectedness of our world and enables us to view ourselves and our physical environment in a more holistic way. This interconnectedness between humans and the environment has an impact on the work of social workers. "Ecological theory provides social work with a framework by which to study, track, and forecast social movement and social change" (Rotabi, 2007, p.125).

A study funded by the U.S. National Institute of Environmental Health Science indicates that unborn children can be harmed when their mothers breathe polluted air. A team at the New York-based Columbia Centre for Children's Environmental Health studied 60 newborn children. They found that exposure to specific combustion pollutants during pregnancy can result in chromosomal abnormalities in fetal tissues (CCPA, 2005, p.31). 
The information emerging from research and literature suggests that it is time to seriously include the effects of environmental destruction in social work education and practice. As Hoof \& Polack (1993) indicated in the article Social Dimensions of the Environmental Crisis: Challenges for Social Work, the social work profession has the theoretical base and practice skills to respond to the social dimensions of environmental issues at the local, national, and international levels (p.209). The social worker's concern about immediate effects of environmental destruction such as lung cancer, asthma, and other health problems are very true. "Sixty percent of Calcutta's population suffer from pneumonia, bronchitis, and other respiratory diseases related to air pollution" (Hokenstad \& Midgley, 1998, p.30). In the United States, asthma increased 40 percent over the past decade. Health researchers found that six out of ten asthma sufferers resided in urban areas where pollution levels exceeded air quality standards (Hokenstad \& Midgley, 1998, p.30). The profession needs to make a commitment to today's reality of the effects of environmental destruction, and contribute to the healing of the relationship between humans and the environment if it wants to be effective in the challenging new reality of the world.

Another interviewee reported, from her professional experience, the relationship between pollution and children's health that: "We see a lot of children here with autism and other sorts of neurological concerns. Not that there is anything definitive; there are huge raging debates about the environmental impact on brain development."

There are growing trends in infertility problems and the effects of environmental toxins which have caused a number of scientists and health care professionals to take a closer look at this relationship (www.greenpeace.org.uk/toxics). According to this website, the 
number of couples in the U.S. with an impaired ability to become pregnant has grown from 6.1 million in 1995 to 7.3 million in 2002. Although some of this alarming trend may be contributed to more people beginning families late in life, it also argues that exposure to toxins such as cigarette, lead, mercury, and pesticides used in agriculture are known to be direct threats to a healthy pregnancy.

A documentary that aired on the CBC in November 2008, called Disappearing Male, indicated that the quality of sperm is declining. A total of 85 percent of the sperm produced by a healthy male is DNA-damaged. The documentary argued that the chemical industry has developed more than 90,000 man-made chemicals in the last sixty years. Of these, 85 percent have never undergone testing for their impact on the human body. It is a deeply disturbing fact of modern life that we inhabit a world that has become increasingly toxic. Our children are exposed to many chemicals throughout their lives. This report provides further indications that we are urgently in need of laws that protect us from continued exposure to these chemicals. The scarce information about the health effects of the approximately 90,000 chemicals in commercial use creates a global environmental threat to our children and the next generation.

Nevertheless, not every interviewee agrees that there is a relationship between the environment and health: "In my day-to-day work, I don't see any relationship between the condition of the environment and the lives of my clients." Another person expressed it in this way:

Well, I think there should be, but for me personally I don't think . . in my direct work. I mean I think the best social worker should be cognizant and aware of this issue. I was thinking about this interview and I was thinking it is a very interesting 
topic. Something to keep in mind, but not something that on a professional level I'm probably thinking and applying.

As we see, despite all the evidence and literature on the relationship between the destruction of the environment and health, some social workers are not able to see this relationship. But, as environmental issues become more public concerns, there are some social workers who are sensitive to this issue and are able to see the link between the destruction of the environment and their client's health. This is probably due to the nature of their work, working with people whose health and well-being is affected by pollution, or some other reasons, but this is beyond the scope of this thesis.

\section{The Environment and Advocacy}

Historically, the social work profession is based on working towards social justice and equality of all people. Human rights and social justice are the core ideas of the profession of social work (Besthron, 2002).

Historically social workers have been agents of change and always fight for change like poverty, justice and . . maybe our next battle is the environment. I also feel there are so many issues in people's life like housing, poverty and. . . that makes it hard for them and us as a consequence for us to pay more attention to our environment.

- Comment by an interviewee

To examine the links between social work and human rights, we have to trace the history of social work's involvement in human rights. Reviews of early social work history remind us that the founders of the profession were involved in human rights 
advocacy. Jane Addams "was at the forefront of the struggles for women's suffrage, immigrant education, health care, children's rights, housing, peace, and progressive education" (Healy, 2008, p.738). She also, according to Healy, organized a number of national and international human rights organizations including the American Civil Liberties Union, the National Association for Advancement of Colored People and the Women's International League for Peace and Freedom (p.738). She was granted the Nobel Peace Prize in 1931 for her leadership in third-generation rights. Another social work pioneer in her efforts to improve human rights was Sophonisba Breckinridge. She was particularly active in international child welfare movements in 1920 (p.738). Other early human rights activists were Abbottin in the USA, Jebb of the UK, Salomon in Germany, Reynolds in the USA and many more, but this is beyond the scope of this thesis. Of the more recent professional social workers who have worked for human rights, there is Farman Farmaian in Iran. She is the founder of the school of social work in Iran and has worked for women's rights and children's rights in the 1930s to more recent times. Some of these figures are described in other works (Ife, 2001; Reichert, 2003; Wronka, 2008). As a result of all these works and advocacy, the UN in collaboration with IFSW and IASSW, published a manual on human rights and social work in 1990. The manual states that:

More than many professions, social work educators and practitioners are conscious that their concerns are closely linked to respect for human rights. They accept the premise that human rights and fundamental freedoms are indivisible, and that the full realization of civil and political rights is impossible without enjoyment of economic, social and cultural rights" (UN, 1994, p.5). 
It then continues:

Human rights are inseparable from social work theory, values, ethics, and practice. Advocacy of such rights must therefore be an integral part of social work, even if in countries living under authoritarian regimes such advocacy can have serious consequences for social work professionals (p.5).

With the current trend of globalization, as these interviewees indicated, it is time to include environmental justice in our concerns as well. Another social worker explained it in this way: "There is a political dimension to the work we do as social workers and we should be advocating on behalf of our clients for their basic rights. Clean water and clean air and adequate and non-contaminated food are basic human rights."

As this interviewee indicated, when we adopt human rights perspectives, it can help us to understand that clean air and water and uncontaminated food are not just needs, but also basic human rights. That in turn will help us to understand the political nature of poverty, discrimination, and environmental injustice. A comment by an interviewee was that: " $I$ think social workers always worked as advocates and working for social justice and having clean water and healthy food is fundamental to our life. Advocacy in these areas is very important."

Given social work's central concern, which is human welfare, it is right time to include and advocate for clean air and water and food which is so essential for the wellbeing of human beings, as the interviewee has indicated. As Coates argues,

Social work has a long history of involvement in social justice issues, and the profession has argued for the rights of all people to an adequate standard of living. As a result, the profession has been active in, for example, urban reform 
and the settlement house movement, community development, and advocacy, feminism and the women's movement, and anti-oppressive theory and practices. This tradition has placed social work in a unique position, both in terms of analysis and action, to take a significant role in addressing the negative consequences on individuals and the social well-being of our culture's environmental devastation (2003, p.3).

As one social worker said:

It is important to advocate for these things: clean air, clean water, good food. And it is in fact in the ethics and practice of the school of social work that we are advocates. And that is our responsibility as well as a privilege that we have from our position. It's a dream because it doesn't happen, but it should be."

But, every change happened because some people had the courage to dream it first. When Mary Wollstonecraft, a forerunner of today's feminists, published Vindication of the Rights of Women in 1792, her views were regarded as absurd. Even Thomas Taylor, a well known philosopher at Cambridge University, published $A$ Vindication of the Rights of Brutes to refute Mary Wollstonecraft's argument to say that if the argument for equality was sound when applied to women, why it should not be applied to dogs, cats and other animals (PETA, 2008, p.2). We should dream it, and then raise our individual and collective voices to change the situation. Without movements for social change, we would still have human slavery, no voting rights for women, legally enforced segregation, and abuse against women and children. Another interviewee explained it in this way: 
I feel there's a reluctance to be political or to be active, or to advocate on an issue and I know we talk about it in the social work profession, but I guess like so many professions there is conservatism and reluctance to stick our necks out. And yes, I think that is something we really need to pay attention to. We have to speak up for what we feel is right. So I believe very strongly that we need to identify those types of concerns and address them in every way we can.

The strength of the profession of social work has been its holistic approach to people and their problems. It developed a practice that considers the social environment that the person is in and includes the person's social environment in their assessment and practice which affects the client's functioning. Now with the reality of globalization, the profession needs to expand its approach and also include the physical environment for its education and practice to be more effective and holistic. As Marie Hoff indicates:

The unique strengths of the social work profession have been its emphasis on a holistic approach to the person and its development of practice methods that address the environment in which that person lives. In recent decades this personin-environment approach has tended toward a narrowly specialized concern with the person's immediate social environment-the context of friends, family, and community that affects the person's functioning. Now the critical condition of the global physical environment is forcing all sectors of society, including the professions, to consider the implications of this crisis. An adequate social work response to the physical environment will demand a more holistic approach to practice through incorporation of the environment, economic, and political 
dimensions of society, as has been suggested by the sustainable development movement (1998, p.27).

Another social worker said:

We need to make a connection between the individual and the collective. We are trained as social workers to sit in our office and look at individuals' psychosocial issues at a micro level. We need to bring a bigger picture into our understanding. So I think it is very important that we are involved in social advocacy and building communities.

From the early years of the profession, social workers have been involved actively to advocate for their clients. They been involved advocating for clients with mental illness, violence against women and children, homeless people, the elderly, and the list can go on and on. They also advocated promoting funding for appropriate programs and resources in their communities to deliver care services to the marginalized and the vulnerable in the population. Today the reality of the world is that we are dependent on each other and affected by each other more than ever. This is a new challenge as well as an opportunity for the social work profession. Social work education needs to respond to this new challenge. As Healy argues: "the growing realization [is] that no nation can solve its social problems unilaterally. Experience with the spread of AIDS, drug trafficking and addiction, the disaster at the Chernobyl power plant, and migration underscore the reality of global interdependence" (1995, p.1509). Therefore, as one interviewee has said, we have to bring a bigger picture to our day-to-day activities. 
Not everybody agrees about the role of social workers to advocate for a healthy environment. One interviewee expressed her ideas in this way: "I think that everybody bears this responsibility; I don't see social workers as having a special responsibility." Another person expressed the same sentiment: "I certainly think we should be aware of what's going on out there in our personal lives. Every person doing what we can in our small way. Reduce, reuse, and recycle as they say."

This view is not able to see the interconnection of people around the world. They see it as something that is happening "there." As long as is not affecting directly in my space, it cannot be my concern. As Coates indicated:

Many people in economically privileged countries are less able to be empathic and sensitive to the devastation and pain which is taking place across the globe. As a result, ecological devastation is not experienced as an assault on "our" community, and the plight of millions of Africans affected by famine or AIDS, for example, is not experienced as a struggle of people about whom Western nations should be politically concerned (2005, p.31).

Sadi, a Persian poet in the seventh century, wrote this poem:

The sons of Adam are the limbs of one body

Created of one essence

When in times of pain in one limb

The others can find no peace

Thou, who has no sympathy for the trouble of others, Is unworthy of the name man 


\section{Local and Global}

Although, in general, the term "refugee" refers to people who have been forced to flee their country of origin because of political and social problems; today it is recognized that refugees also include people who have been displaced because of environmental adversities. "Natural disasters and other environmental problems in themselves have in the past been a major cause of involuntary population movements" (Mupedziswa, 1998, p.114).

One interviewee states: "We need to know about what's happening in the environment locally and globally because it will be impacting our clients' lives. Some clients we see are also from different countries and have been deeply affected by the condition of their country's 'environment'." The literature on this issue indicates that climate change could be a trigger for people (especially in dry areas and developing countries) to immigrate to other places (Meze-Husken, 2000; McGregor, 1993; Gachuruzi, 1996). One of the groups in Britain, Christian Aid, warned that because of increases in temperature, in 2050 the number of refugees will reach one million people. The report indicated that by 2080 one to three million people will not have water to drink (BBC Persian, 2007). It is predicted that the destruction of the environment will affect more people in Africa, South Asia, and the Middle East.

The profession has long been involved in counselling individual refugees and families to cope with their new reality. With the new reality of the world, social workers will probably encounter more people who have been displaced, not because of political and economic reason, but also environmental destruction. Another interviewee states: 
I believe local, national, and international are related and we need to have a better understanding of what is happening across the globe. But at the same time what affects us is our immediate environment and knowing about it makes our perception more concrete.

Here, an interviewee talks about what some call "global consciousness" (Coates, 2003, p.96). This global consciousness is our understanding that we are all connected to each other and to other non-human life forms and nature as a whole. By acquiring this global consciousness we learn how our individual actions will affect others as well as nature as a whole. We learn that, through our personal, collective effort, we can provide social, economic, and political opportunity for everyone, everywhere. As Coates indicates (p. 96):

Learning to act from a "whole system consciousness" involves awakening all our capacities--spiritual, social and rational/scientific--to work toward higher consciousness, greater freedom and increased complexity. Our human purpose is released through action, as we are able to see the connection between our unique ways of contributing to the world.

One social worker said:

I believe we have the responsibility to be aware of what is going on at the local, national as well as international level. I don't think we can really separate them. Also I think it is interdisciplinary too. I have a good friend who is a physician and aside from her daily work she is part of a network of physicians who are very much concerned about environmental impacts on human health and so we have a lot of conversations and I think that is important. You don't just look through the 
lens of social impact of the physical; you have to look at a broader picture in a more holistic way and make connections.

In mindfulness living, we are able to see our individual actions as they relate to others and through collective actions we can create a better world for the whole. As Coates argues (p.97): "Within this unfolding world view, an objective for social work is to help bring about a transformation of society into one with a vision and mandate that recognizes that we are intimately and symbiotically connected with nature and all people."

It is safe to say that the world is now linked and interconnected through the global market economy. Because of it, a socio-economic problem in one country has an effect on many countries. The best recent example is the collapse of the banking sector and other corporations in the U.S. and the effect that this had on the economy of the world. Another example is the recent restlessness in Greece and its effect on the economy of the rest of Europe. As Besthron indicates (2002, p.80) social service in such cases requires coordination of government and non-government organizations at international, national, and local levels. The social work profession is able to see people in their social environment. However, there is a gap. This gap limits our capacity to respond to the demands of the new millennium which result in the destruction of the environment. The social work profession has to include this new challenge in its vision if it wants to be effective in this new millennium. 


\section{Social Workers' Awareness of Environmental Crisis}

In this category, all the interviewees indicated that the environment is in total crisis. There was not even one disagreement among the interviewees. It shows the importance of the environment in public opinion and their attention to what is going on in terms of the environment. The answers were: "I think it is worrisome, in terms of global warming. I think we need to keep in our mind set and pay attention that we impact on the environment." Another comment was "It is a mess."

One interviewee sees the problem in a political way. She describes it as such: "Terrible. Well, on a local level it's all very political. There is an expression 'smoke and mirrors' of political well-being or of health care well-being, and on the surface they look good. But the follow through is not there .... The environment is devastating physically and politically."

Some show loss of control at being able to do anything about the issue: "I believe global warming is a reality. I am worried about the food I eat and especially all these chemical products in our homes and their effect on the environment. I don't believe I have a lot of control over what I put in my mouth or the air I breathe. I am worried about our environmental problems." This kind of pessimism is echoed by other interviewees: "I think that the environment is in grave danger, and that little can be done to reverse this."

One social worker talks about the effects of the environment on her clients' lives. As evidence of this effect she adds:

Well, I think probably some of the things that come to mind immediately I think as we make poor decisions in how we live is our physical health is deteriorating and 
the health of our planet is deteriorating and this causes huge stress to people and social environments. We see a lot of children here with autism and other sorts of neurological concerns. Not that there is anything definitive; there are huge raging debates about the environmental impact on brain development. But my personal belief is I very much lean towards the evidence that points toward a strong connection.

As the above interviewee mentions, there are great effects on the health of individuals as a result of environmental degradation. There is evidence that shows a link between air pollution and infant mortality, cardiac, pulmonary, and cerebral vascular disease (Donohoe, 2003, p.574). The same author suggests that in developing and poor countries, the problem is even greater: "Air pollution kills 40,000 people prematurely each year in India" (p.574). Social workers, because of their interaction with individuals, families and communities, are in a position to recognize the cause and effects of environmental degradation and social injustice and act on them at different levels. These range from interaction with individuals, families and communities, to direct involvement in politics or activism.

In this category, I have identified the following themes which represent the views of the interviewees:

Shallow Ecology

Deep Ecology 


\section{Shallow Ecology}

In the shallow ecology theme, the interviewees avoided fundamental questions about their values and their personal lifestyles that have created this environmental crisis (Badiner, 2002; Besthron, 2006, 2004, 2003, 2002, 2001; Fox, 1989; Ife, 2002; Naess, 1995). In this approach, they are able to see environmental issues as one of the greatest challenges facing humankind but they are not able to challenge the social cultural system that exists and our lifestyle which contributes to what one interviewee calls "the mess." In these themes, the interviewees are not able to go beyond the dichotomy between human and non-human, the relationship between humans and nature. Their concern is people and their health. Mankind is the centre of the world. This view is anthropocentrism. Fox describes anthropocentrism as "human self-importance" (1990, p.9). He suggests that it has been the core philosophical, social and political tradition of Western society since the time of the classical Greeks. Interviewees see the problems in isolation and are not able to see them in a more holistic way and are unable to see our relatedness and connectedness to each other and to nature.

I believe that our contacts can use the environment in a healthy way. If they look at the necessities of air, of plants, and of light I think it is possible. So the buildings we live in, work in, the park that we use, the space we have around us, I think that all of that can be used as development, but it can be done in an environmentally open way. I would like to see things last longer, so that when my computer or phone breaks I can fix it. But I also understand that technology advances. 
In this opinion, the focus is only on human health and well-being. The interviewee's language: buildings we live in, work in, the park that we use, the space we have around us, are all indications of shallow ecology. It is indicative of a human-centered paradigm. The focus is on human health and well-being only. With shallow ecology, people start from the point that other non-human beings are not as important or have less value. In its extreme manifestations, the Earth is seen as a resource just for human use and misuse. There is not the ability to see our interconnectedness. This is what Naess $(1995, \mathrm{p} .4)$ calls "the attempt to ignore our dependence and to establish a master-slave role."

One interviewee dismisses any relationship between local and international, which I consider to fall in the shallow ecology category. "People living in a specific location make their own decisions, but I am not sure that some of our decisions about treating our environment have affected people in Africa or South America." This view fails to understand the impact of our actions and lifestyles on others. It is unable to see the interdependence of the world. The world is not a separate entity, but contains intersecting fields of process. As Alan Drengson, Associate Professor of Philosophy at the University of Victoria, in his essay Shifting Paradigms: From Technocrat to Planetary Person (1995, p.87) indicates:

We cannot isolate our actions from the rest of society, nor from the rest of the ecosystem. Polluting the water in the stream that runs through my yard can pollute all water in the drainage. The ground water polluted by radioactive wastes can pollute the river, the ocean, the biosphere. Unlike a machine, the organism is a complexly interrelated whole of processes, with both internal and external principals of organization. The ecosystem is like a living body. 
Shallow ecology accepts that there are serious environmental problems, but has faith that science and technology will be able to deal with toxic waste, and provide food and material for adequate standards of living for all people. It fails to understand that to solve this crisis we need to seek a new relationship which is not based on exploitation and domination. But, as Coates indicated, "Such a relationship demands a new vision, a vision which recognizes human dependence on the Earth and the importance of a healthy planet for the health and fulfillment of humanity" (2003, p.2).

However, the social work profession, despite its long tradition of being active for social issues for an adequate standard of living for people (i.e. settlement housing, community development, and anti-oppressive theory and practice), has not considered the environmental crisis which affects people lives seriously; "nor has it considered the tasks and demands of a new vision" (Coates, 2003, p.3). This new vision can provide humanity a basis for solving the problems created by humans and the social and psychological problems that result. This new vision is presented by the deep ecology movement.

\section{Deep Ecology}

Contrary to the first view, some interviewees were able to move beyond shallow ecology to have a more holistic view of the problems which are faced by humans.

We read and use the terms such as "global village" and "international interdependence" regularly. Despite the reality of boundaries between countries, more people are aware and appreciate their place in a complex worldwide system of global activity. Today, when we consider the revolution in communications, the possibility to travel and to be exposed to other cultures in a matter of hours, the increased global trade and political cooperation, it 
makes it possible for what some writers call the "globalization of the human experience" (Midgley, 2001, p.22). Social workers are no exception, and cannot afford to be in their "cocoon" of local thinking anymore, particularly if they want to be effective and proactive in the new millennium.

In terms of the correlations between destruction of the environment and violent conflicts, there are studies by some authors (Baechler, 1998; Hoff \& Rogge, 1996; Marlow \& van Rooyen, 2001), which argue that violent conflicts are triggered by environmental disruption. "Environmental conflicts manifest themselves as political, social, economic, ethnic, religious or territorial conflicts, or conflicts over resources or national interests, or any other type of conflict. They are traditional conflicts induced by environmental degradation" (Baechler, 1998, p.24). Degradation of the environment has the potential to become an international peace and security challenge in the future.

One interviewee acknowledges the role of developed nations and the developing ones as such: "Much of the environmental abuse began with industrialized nations; now developing nations and people living in them are suffering most of the environmental problems. There is a direct link between social justice and the environment."

There is no doubt that the level of consumption in North America, as explained in the introduction, is much higher than the rest of the world. As a result, people who live in developing countries are paying the price. As Laura Landon indicated: "If everybody consumed at American or Canadian levels, we would need five additional planets to provide the needed resources and absorb the wastes produced" (CCPA, 2004, p.34). But the people in developed countries resist this idea because the economic and cultural 
structures are designed to promote consumerism, and greed fuels the engine of capitalism.

Industrial societies may resist the idea that consumption levels in these countries will have to be drastically reduced, while living standards in third world countries must dramatically improve, together with human population stabilization and reduction among both rich and the poor countries, it is now clear that there will be no solution to the environmental crisis without such a move” (Sessions, 1995, p.61).

As another interviewee said: "It seems the message to us is we need to change our lifestyle because it is impossible to find a way to change without cutting our wasting lifestyle." They went on to say: "Most recent environmental disasters happened in developing countries caused by deforestation, global warming. In the Canadian north, also, the lifestyle of many aboriginal people is in danger because of global warming."

As this social worker made clear, there is no chance that we can avoid major disasters without changing the current direction. "Those who see the problems in isolated ways compatible with mild reform and those who see the problems holistically as requiring a deep change in our form of life” (Drengson, 1995, p.75).

One goes further and says: "Certainly with climate change, it is going to have an economic impact on people everywhere. It's going to also have a social impact and political consequences. Political and social unrest happens when the situation in the environment does not provide adequately for people." This interviewee is expressing the same concerns as scientists and environmentalists; warning that deterioration of the 
environment and the continued struggle for natural resources may contribute to conflict in the future (Hoff \& Polack, 1993, p.206).

Another interviewee connects social justice to the environment. As she said: "Concern for social justice would also include concern for the environment. Human creatures, animals, fish etc. all need to be protected and honored. Without environmental justice we won't be able to have social justice because the earth won't be able to sustain human beings." This interviewee represents deep ecology, recognizing the need for a new paradigm of human-environment relations; a new vision which is egalitarian and has value for all life, a new vision which is able to see the connectedness of all beings and the effect of it. The fact is that we are not living in isolation from each other nor from nature. "The world must be thought of as intersecting fields of process, rather than as separate individuals. We cannot isolate our actions from the rest of society, nor from the rest of the ecosystem" (Drengson, 1995, p.87). Furthermore, "everyone has the right to clean air, clean water, and adequate food and the creatures of the earth have a right to these things as well." The interviewee is talking about what experts call "third generation human rights" (Ife, 2001). The fact that the rights of the individual are not just voting, freedom of speech, or equality before the law, but also the right to breathe clean air, drink clean water as well as the right to experience nature (Ife, 2001).

So far, I have presented the interviewees' assessments of the status of the environment. All of them, with no exception, agreed that the global environmental situation is in a state of profound crisis. The air is polluted, drinking water is contaminated, and the food that we eat is poisoned. We learn every day through the media of the loss of wilderness, deforestation, global warming, and climate change. We 
are warned by scientists and the experts that the earth is in a state of crisis. Therefore, it is not possible to ignore environmental degradation any longer. It seems that social workers are no longer ignoring the link between the well-being of the physical environment and the well-being of humans.

\section{Is Awareness of the Environment Important to Social Workers?}

Opinions in this area vary according to the beliefs and personal commitments of each individual. For some interviewees, the perception was that it is an important issue for social workers. "I think the best social workers should be cognizant and aware of the issue." For others, it was important at a personal level, but not at a professional level. "I think that everyone bears this responsibility; I do not see social workers as having special responsibility."

Below, I present different views on this issue:

\section{Awareness of the Physical Environment}

In this view, the interviewees' awareness is limited to the physical environment that their clients live in. They believe that it is their responsibility to learn about the aspects of their clients' physical environment that would affect their lives: "I think it is definitely our responsibility in the one-to-one role. In my work, I work with the geriatric population. There are certainly some of these issues there as well. Limited incomes, inadequate housing, and social isolation. Surely, that's impacted the environment where they live." 
In this statement, the social worker dichotomizes the person and the environment by narrowing the definition of environment to the relatively small scale of personal: inadequate housing, social systems, and social isolation, in which the client is involved. Some authors and scholars have emphasized the need for social workers to correct this vision by including the importance of social context as well as relations between micro and macro (Besthron, 1997, 1999, 2000; Germain, 1979; Hoff \& Polack, 1993). As Besthron indicates, social workers need to include "the necessity of discussing human beings not merely in the context of relationship between individuals and the social environment, but also in the context of relationship between persons and nature" (2002, p.95).

Another social worker says: "We're part of the environment; we exist in an environment that's going to have an effect on us. So we need to be aware of how it's impacting on human beings." This social worker's statement represents the deep ecology philosophy by indicating that we are part of the environment and not separated from it. The fact is that our well-being is related to the well-being of nature as a whole. It stresses that human problems will intensify when we ignore the damage that is done by humans to nature. It confirms that damage to the environment by human beings will and is impairing the life web upon which we are all dependent. As Mathews (1990, pp.159-166) expressed, the whole is more than the sum of its parts, and the parts are defined through their relations with one another and the whole.

One social worker uses her personal experience in her daily work with women to present her point of view: "I have worked with women who have suffered or survived breast cancer a lot of times. They are trying to understand why there is so much cancer 
these days. Sometimes people talk about food safety and organic eating and why it is important to their health." Another social worker who works with children explains it in this way: "There are many things that we are doing to our environment that have a huge impact on our health and the health of our clients. $C B C$ did a documentary about environmental contamination and baby brains, particularly boys. It was very powerful and actually it was sort of groundbreaking and shocking."

It is well documented that children are more vulnerable than adults to environmental problems. Statistics indicate increases in cancer among children as well as respiratory diseases as a result of pollution (Hoff, 1998). In the past decade, there was a 40 percent increase in asthma among inner-city children (Hoff \& Rogge, 1996, p.43). Lead poisoning was another health problem as a result of environmental problems. Social workers, especially those who have been concerned with social, political, and economic inequality, have advocated for change in these areas for decades. Now it is time to also include social justice for future generations. To reflect on how our current lifestyles are going to affect future generations: "This concept of intergenerational equity, profoundly moral in character, is violated in numerous ways by our society" (Hoof \& Polack, 1993, p.208).

Social work humanistic foundation and social work skills provide the profession with the opportunity to be proactive and to play a role in healing individuals, families and communities to understand our moral obligation towards the next generation. One woman suggests we should include physical environment in our assessment:

I think, in our assessment, these days, we have to ask people about their environment that they are living. Whether it is healthy or not. Physical 
environment of where people work in terms of chemicals they work around. Living in a very toxic environment. Working around chemicals. These are environmental issues that we have to consider in our assessment.

As we noticed, there are concerns about the well-being of human beings and the state of the environment. Interviewees believe that the assault on the environment is affecting the well-being of humans and they are able to relate the consequences of this assault to their daily work. But they see nature as something separate from humans, and humans are seen as the centre of concern about what is going on with the environment. This is what experts call shallow conceptualization of nature; something that is separate from humans and humans are the centre of importance.

A more progressive way of thinking regarding nature and humans suggests that humans are not separate but a part of this web of life which we call the universe and are not separate or more important than nature. This alternative way, as discussed earlier, is represented by deep ecology and ecofeminism. From this alternate environmental perspective, the crises in nature and humans are interrelated. Nature is not seen as something existing just for the benefit of humans. From the social work perspective, it is important to also include the physical environment in our traditional focus of social environment. The social work profession is concerned with the well- being of humans. Therefore, we have to consider the relationship between the well-being of nature and the well-being of humans. 


\section{Awareness of Justice and the Environment}

In this theme, some go further and talk about the responsibility that social workers bear in terms of justice. They believe that social workers are agents of change and always fight for change in terms of social justice and social inclusion. They suggest that it is time to also include environmental rights:

Historically social workers have been agents of change and always fight for change like poverty, justice and... Maybe our next battle is the environment. I also feel there are so many issues regarding people like housing and . . that makes it hard for them and as a consequence for us to pay more attention to our environment.

In this statement, the interviewee correctly indicates that social workers have historically been agents of change. They fought for poverty, racism and whatever was unjust in society. But, we forgot that the physical environment was part of the development of the social work profession. The history of social work indicates that Jane Addams and her colleagues in the settlement movement advocated for the improvement of poor urban environments in poor neighborhoods where unsanitary conditions created dangerous physical and mental heath for people (Hoff \& Rogge, 1996).

Another social worker relates the environment to poverty: "The poverty of some families is most certainly related to environmental conditions. For example, displacement and destruction of home and belongings can be directly linked to environmental disaster."

Even though it is difficult to distinguish natural disasters from those resulting from manipulation by humans, recent evidence suggests that there is a convergence between social disadvantage and the risk of exposure to natural disaster (Hoof \& Rogge, 
1996). The best example is the recent case of Hurricane Katrina in the United States. The impact of Hurricane Katrina on New Orleans illustrates the point. "New Orleans was a city of great disparities, a city of distinct neighborhoods highly segregated by color and income" (Park \& Miller, 2006, p.13). Examination of the impact of Hurricane Katrina on poor and disadvantaged people showed that because they lived mostly in the lower-lying, and therefore, more flood-prone sections of the city the impact on them was devastating ((Park \& Miller, 2006, p.14).

One interviewee even goes further and perceives the impact of the global environmental crisis and its impact on her clients: "We need to know about what's happening in the environment locally and globally, because it will be impacting our client's lives. Some clients we see also come from different countries and have been deeply affected by the condition of their country's environment."

This ecological consciousness is being aware of our connection with others and with all life. This consciousness is an awareness of the bond of all human beings and Earth as a whole and does not accept any boundaries for compassion. Considering that human welfare is the central concern for social workers and we spend our working lives addressing any form of the problems that affect the lives of our clients, such as drugs, violence, abuse, and so on, why not also include environmental welfare in our profession?

Another interviewee takes it further and talks about the responsibility of the developed nations:

I think that we know that people that are suffering the most from climate change are the poorest of the poor. There is an island nation in the South Pacific near 
Tonga. They are relocating people because they are under water and the rest of them will be under water in 20 years. The wealthy can figure out ways to take care of ourselves and we are somewhat buffered from the effects."

This view represents what some call "Global Consciousness" (Midgley, 2001, p.25) which is slowly emerging among people and, as we see, among social workers as well. Today, the majority of social workers are engaged in working with individuals and families to treat the problems that they are facing. The profession uses psychological behavioral and treatment theories to deal with problems. Some argue that the profession has not responded to the challenges of the new reality of the world. One of the critics of the school of social work, for not exposing students to the importance of acquiring an international perspective in today's age of globalization, is Healy. Healy believes that schools of social work are not adequately exposing students to international content (Healy, 1995). The history of the profession indicates that the social work profession gradually distanced itself from the political activism which was in its early days.

In the United States, many social workers associated with the settlements at the turn of the century campaigned for progressive social improvements, and in the 1930s the rank and file movement was inspired by socialist ideology. These social workers collaborated with the labor movement to advocate for progressive change. In the United Kingdom community work has long been identified with a vigorous form of local activism that challenges established political and social practices. In the 1970s many social workers in Latin American countries were inspired by the writing of Paulo Freire, and sought to apply his ideas into social work practice. Activism also found expression in the efforts of some social 
workers to challenge oppressive dictatorship in countries such as Chile and South Africa (Midgley, 2001, p.29).

What the social worker indicates in her statement is the gradual emergence of a global consciousness and solidarity in the age of international interdependence.

\section{Awareness of Politics and the Environment}

In this theme, we see two visions: one towards the local; and the other towards the local and international level. One participant said: "The poverty of some families is most certainly related to environmental conditions. As mentioned above, displacement and the destruction of home and belongings can be directly linked to environmental disaster."

The severity of environmental problems is slowly but surely entering the awareness of the general public as well as social workers. In the above statement, the social worker acknowledges the relationship between the destruction of the environment and poverty. This statement reinforces that social issues and environmental problems are connected. More and more people are recognizing the effects of environmental problems and the welfare of humans. Ironically this risk is shared by poor people in developed and developing countries. "Populations at risk range from the poor who live on deforested hills in India and Bangladesh to poor people who live in trailer courts on the Atlantic coast of the United States" (Hoff \& Rogge, 1996, p.47).

As was mentioned earlier, there is a link between poverty and environmental destruction. An unpredictable climate will profoundly affect people who are already living in poverty and may result in deeper poverty. As experts indicated (Agarwal, 1996; 
Borges, 2007; Brocklesb \& Hinshelwood, 2001; Shiva, 2005), environmental disasters such as flooding, fire, deforestation, or pollution may push already poor people to extreme poverty or even force migration to other places. In this case, they add to the number of urban poor and the expansion of the shanty towns which already exist, or they rebuild their destroyed communities, which pushes them to even further poverty due to limited resources.

Another interviewee talks about the day-to-day life of their client which could be affected by environmental issues: "This condition [means environmental] affects our clients. Understanding these issues is necessary to help our clients' negative daily life as a result of it." What this interviewee is saying is that the condition of the environment can be an antidote to the negative daily modern life. Studies show that when people are under stress, nature can have a restorative influence (Besthron, 2003). Also, nature seems to have a positive effect on our emotions, promoting "friendliness, playfulness, elation, and affection" (Besthron, 2003, p.9).

Nature, and all forms of it, is an ingredient for healthy human beings. We are so interconnected to each other beyond our present knowledge and awareness. As Besthron in his article, Nature, Genetics, and the Biophilia Connection, explains:

When we do not respect the worth of the natural environment, we do not respect the worth and dignity of the people who reside in and depend on it. If social work is to continue its focus on poverty, discrimination, oppression and other forms of social injustice, as well as its emphasis on respect for diversity, it must begin to take a far more active role in the eco-justice/social justice dialogue (p.12). 
One interviewee mentioned our ethical responsibility to advocate for our clients in terms of clean air, water, and food. She said:

We have the responsibility to advocate for clean air, food, and water for everybody. We do not have the responsibility to provide, but we have the responsibility to advocate. And it is in fact in the ethics and practice of the school of social work that we are advocates. And that is our responsibility and privilege that we have from our positions.

This statement confirms the importance of the third generation of human rights which was discussed previously in the principles of human rights, at least, for some social workers: the right to breathe unpolluted air, access to clean water, and the right to experience nature. Human rights have evolved over the centuries and now are the time to pay attention to, and include these environmental rights in our assessment.

Some go further than the local and talk about international effects of environmental disaster: "Most recently environmental disaster happened in developing countries, caused by deforestation, global warming. In the Canadian north, also, the lifestyle of many aboriginal people is in danger because of global warming." In this view, the social worker is able to see the impact of destruction to the environment to developing countries and, not so far away, to the Canadian north. She is concerned about the negative effects of severe environmental issues facing human communities. As I indicated before, the Inuit's diet is contaminated with mercury and toxins such as PCB, which can endanger their health because polar bears are now ingesting greater quantities of these toxins (The CCPA, 2005, p.17). Another example is Canada's Aamjiwnaang people in southern Ontario. Women in this small community are suffering a high number 
of miscarriages and local schools are reporting an increasing level of learning disabilities among students because these people are living in the middle of an area which contains 20 percent of Canada's chemical refineries, according to CCPA (2005, p.17). Given all of this information, social workers have an ethical obligation to advocate on behalf of these communities and the people who have been affected. And:

Recently there was an interesting story, was it in the . . asbestos products perhaps construction in India. I think that's very questionable and very concerning. So here we are in this business, in this industry of Canada sending something that is in some ways helpful in the terms of cheap housing construction. But in terms of health, in the air there and then breathing it in. I am thinking that's not right. So there it is political, it is industrial, and it's environmental.

The case of Bhopal is one of the most appalling examples of corporate abuse, which is what the interviewee is talking about. Twenty-seven years ago, thousands of people died from breathing in gas, water, and other chemicals in Bhopal, India. Within three days, up to 10,000 people succumbed to their injuries from the gas. According to Amnesty International (November 2009), doctors were frantic, not knowing what antidote to administer because Union Carbide management refused to divulge the chemicals in the mix. Even now, about 15 people still die from gas-related conditions each month. As Amnesty International reported in 2004, compared to its sister plant in the U.S., the Bhopal factory was built with critical differences in levels of design and operation in the midst of poor, crowded neighborhoods. It was a disaster waiting to happen. People in the area still suffer from high rates of cancer, respiratory illness, immune disorders, anxiety 
and depression according to Amnesty $(2009, \mathrm{p} .11)$. This case clearly illustrates the crime against poor and voiceless people because of corporate greed.

And: "We're affected by the entire earth and global political structures. Everything is interconnected in our world." And: "We are a global village. We are a global community. I think we have a responsibility as social workers to expand our understanding and our knowledge about global issues and environmental issues. Because it will affect us all."

Another comment:

I worry about [this situation]. It is a sort of instability in our country and in the world and that is expected when you look at what we are doing to this planet. It's enormous and it's the whole interplay, not just the environmental effects that we are talking about here and also economic policies and more and more people suffering. A widening gap between the very wealthy and very poor and destruction of community, all of those things. I think we are seeing huge instability.

But, not everybody agrees with the advocacy role of social workers in this matter: "I think that some social workers can take on this role if they choose, but I certainly would not state that all social workers must take on this role." Another interviewee said:

For social workers it is important to be exposed to the fact that there are systematic environmental problems. Learn about it, what you do about it is your right. In my opinion, I like to do that when I can but I can only do what I can do. So, I do not want to be told as a social worker that you must go out and advocate. 
One expresses it in this way: "Not everyone is an advocate, but we can all support advocacies. There will be people on the front line and others who with our beliefs and values support that work i.e. giving donations to environmental causes, etc."

In this theme, social workers talk about the effects and consequences of the assault on the environment. They rightfully are worried about the future. As experts estimate:

Today 505 million people live in countries that are water-stressed or waterscarce; by 2025, that figure is expected to be between 2.4 billion and 3.4 billion. In 1960 there was an average of 0.44 hectares for each human being on the planet; today there is less than one quarter of a hectare. Today, 1.8 billion people live in 40 countries with less than a tenth of a hectare of forested land for each person. By 2025, this number could nearly triple, to 4.6 billion. In 19 of the world's 25 biodiversity hot spots, population is growing more rapidly than in the world as a whole" (Besthron \& Wormer, 2007).

\section{Participants' Proposals for Awareness Raising}

Here I identify and categorize the different ways in which interviewees suggested improvements in social workers' awareness of environmental conditions. The answers vary from spending time in natural settings in order to appreciate nature more, to being an activist, offering courses in schools of social work, to providing environmentallyfriendly work places and living spaces. Below, I present three different themes: 


\section{Having Contact with Nature}

The solution presented here is at the personal level. The interviewees suggested that contact with nature will promote more appreciation of our environment which will reduce or prevent their abuse of it:

We think as human beings, we are great, big, intelligent, but when we go to nature, when we see the grandiose of the environment, we realize how small we are. Having contact with nature will help us to understand that we are part of it, not separate from it.

Another social worker said:

When I go to nature, I realize how small we are in this whole web of life; how much we are dependent on nature, despite the fact that we think we are stronger than nature, that we can change it for our benefits. All is illusion. We are not and we cannot.

Another interviewee again stated that having contact with the environment is her way of building appreciation for it: "I think you can answer it in many ways. This may not be the way most people answer, but for me I think spending time in nature is the most powerful way to deepen your awareness and appreciation."

Social workers in this theme present a strong connection between humans and the environment. In this regard we can refer to "the Biophilia Hypothesis" (Besthron, 2003), which argues a strong genetic predisposition for nature and natural settings. The Biophilia Hypothesis argues that human beings benefit from interacting with nature. Also, there is a "genetically-determined need to deeply affiliate with natural settings and life-forms" (Besthron, 2003, p.1). According to this theory, this affiliation is an integral 
part of healthy human development. It means that human beings have a need to connect with nature to feel fulfilled. We, as humans, know this affiliation without thinking about it. For example, during weekends in the summer, people leave the cities and go to their cottages and other places to benefit from exposure to nature. They see trees, wild flowers and hopefully some birds. Some of us go to Africa or other exotic places to see the wild life to promote appreciation of the natural environment. There are studies that suggest that exposure to natural scenes decreases the heart rate, lowers blood pressure and inverts alpha brain waves (Besthron, 2003, p.5). But, despite all of this evidence, the social work profession has tended to neglect the natural environment and sees nature as something outside its professional responsibility.

The therapeutic effects of connecting with nature are now used by some social workers to promote healing in the lives of their clients and to even mitigate risk in some children at risk (Hoof \& Polack, 1993; Ungar, 2003). As Hoof and Polack indicate: "Wilderness experiences as therapy for delinquent or disturbed adolescents indicate professional recognition of the association between the physical environment and human social functioning” (p.206).

\section{Promoting Environmentally-Friendly Practices in Workplaces and Living Spaces}

While the overall suggestion is at the personal level, the solution presented here is more due to work environment and choices that we make in our living space.

I think there is a responsibility individually as well as the person who is part of this concerning issue to be aware of it, to do what we can do individually. 
Whether it's in the sort of day-to-day working or in our personal life style. You know, $I \ldots$ it is my concern about recycling in this agency. I think this is an environmental issue. We seem to struggle with that. I certainly think we should be aware of what's going on out there and in our personal lives. Every person doing what we can in our small way. Reduce, reuse, and recycle as they say.

Another one suggests taking a more active role:

As citizens we have to be responsible and some agencies have taken steps to measure their footprint. I raised issues with my manager about recycling and . . which later on with much support within the agency, management took more steps to lower the agency's foot print.

Here, as we see, the interviewees make some suggestions to promote environmentally responsible conduct in agencies regarding respect for nature. We all can do something, in our work place or in living situation, to promote respect for nature such as using or pushing for the use of energy efficient lighting, recycling, and the use of nontoxic cleaning materials. Other suggestions would be investing in environmentally responsible companies, such as through RRSP stock purchases, and if financially possible, installing solar panels in our homes and suggesting them to our agencies. Deep ecology can lead to positive environmental conduct in the organization such as:

The use of energy efficient lighting, water saving plumbing, recycling programs, recycled paper and other materials, nontoxic cleaning materials, car pooling, safe disposal of toxic and no biodegradable waste (such as medical waste, discarded computers), purchase from and invest in environmentally and socially responsible companies ((Besthron \& Canda, 2002, p.94). 


\section{Offering Environment-Based Courses in Social Work Schools}

Offering courses and workshops to students of social work are seen as useful in order to increase the awareness of students with regard to the environmental problem and its effect on the lives of our clients. Interviewees offer the following comments:

As human beings we're impacted physically, spiritually, emotionally, materially, socially. Social workers are called to seek to help people and therefore it's important that they recognize this relationship. It is the responsibility of schools of social work to include this understanding in their curriculum.

And: "Educating ourselves, reading, talking to people, taking courses. Social work colleges should be offering courses on this issue." Also: "Government funding for social work schools, maybe funding so social work schools could liaise with groups working on environmental issues so they could meet for a conference to discuss these issues."

Other interviewees suggested starting with small groups of social workers and inviting a speaker to educate them in this regard: "Perhaps starting in small groups, bring in a couple of speakers, have a chance for question and discussion." Another interviewee suggests: "The forum of social work institutions, our university faculties, and our association."

Some suggest that the provincial organization of social workers should pay more attention to this issue:

As a provincial organization there are ways that we need to be paying attention to

it. What about schools of social work? Social workers are again very people 
oriented so we should be contemplating the environment and having an impact. I am not quite sure of the mechanism but there are ways to do it.

And:

Historically we understand the relationship between health and poverty or hunger but we less understand the relationship between what we put in our mouth (chemical and so on) and with our health. So why not courses like environment and health or the relationship between food and the environment.

One social worker looks at the issue in a more holistic way:

Well, I think we should whether it's a specific course or whether it's a part of every course, because it isn't anything that is separated; all the issues come together. So, in a course about poverty, we can talk about the physical environment and the repercussions. In a course about understanding legislation then we need to talk about the environment that those pieces of legislation are impacting. I suppose it could be done in a course but I would like to see every course talk about how when we do social work with a client, that we need to take that into account into our assessment.

Some suggest more of an advocacy role: "Historically we were involved to advocate and work with different levels of government to effect changes. I don't see why we don't have to do it with this issue if we believe environmental issues are affecting people's lives." One goes further and suggests being more politically active: "Well I think . . I don't know how things happen, but I would think there would need to be some demonstration of demand and a demonstration that it is relevant to practice, so I think that the research you are doing has got to be interesting in that regard." 
Another person suggests people who have the same passion get together in their workplace and raise awareness about the issue: "People need to make those connections and build those relationships whether it is an online forum or meeting for coffee for social workers in one setting who share a passion on the issue to raise awareness together. I think there are so many different ways to do it." The majority of participants are aware of the importance of the environmental issue and the need for more education in this matter, either through personal effort or formal education.

The notion of physical environment is absent from social work practice and education. The profession defines environment as just the social environment. Even when acknowledging the physical environment, it is the shallow ecological conceptualization of nature as something separate and "there." Deep ecology and ecofeminism offer a different and holistic view: "It suggests the necessity of discussing human beings not merely in the context of the relationship between individuals and social environment, but also in the context of the relationship between person and Nature" (Besthron \& Canda, 2002, p.95).

\section{LIMITATIONS}

Like any other research, there were limitations in this research study which must be noted. First of all, the number of participants was small. Therefore, it cannot represent the view of social workers in general. Probably the result would be different if the sample was larger. Also, considering the time frame and the fact that the questions were short and based on basic information, the results cannot be generalized and applied to all social workers. 


\section{SUMMARIES OF FINDINGS}

There is serious concern regarding the assault on the environment all over the world. Research shows that the air is polluted, drinking water is contaminated, and food that we eat is poisoned. The effects of global warming include: increased rates of cancer, asthma, and other respiratory diseases. "In the United States, where asthma increased 40 percent over the past decade, health researchers found that six of ten asthma sufferers resided in urban areas where pollution levels exceeded air quality standards" (Hoff, 1997, p.27). Despite this global concern, the social work profession is completely absent from this debate, let alone being active in this life and death situation. Despite many scholars and writers in the field who define the environment as both physical and social (Besthron, 2003, 2002, 2001; Coates, 2005, 2003; Germain, 1979; Hoof, 1998, 1993; Ife, 2005, 2004; Ungar, 2002).

However, as we noticed in this exploratory research study, the social workers who participated were overwhelmingly aware of the environmental crisis and the effects of this crisis on the physical and mental health of the people that they work with.

This exploratory study examined opinions, awareness and understanding of social workers concerning the extent of environmental destruction and its importance to the profession. It was encouraging that all social workers who participated in this study indicated that there is an environmental crisis. And the majority of them felt overwhelmed by it.

The social workers who participated in this study asked questions to clarify the definition of the environment for them. For four out of eight of them, the term 
environment means the physical environment. For two out of eight of them, it was the social environment as well as the physical. The remaining two defined the term as a context, which could be social, physical, and cultural.

Some social work scholars and writers have taken the challenge of considering including the importance of the physical environment as well as the social environment in the social work profession (Besthron, 2003, 2002, 2001; Fox, 1989; Hoof, 1996, 1993; Ife, 2007, 2005). Some point to the links between environmental destruction and racism and poverty as well as health problems (Besthron, 2004, 2002; Borges, 2007; Bullard, 2002, 1993; Donohoe, 2003; Hoof \& Rogge, 1996; Ife, 2003). These educators are bringing into social work "the awareness of a healthy earth if people are to lead healthy lives" (Coates, 2003, p.56). To be able to be guided by this new awareness, social work education needs to move out of its reactive role and become more proactive, as Coates revealed: "Social work needs to step outside traditional modes of thinking and action embedded in the industrial enterprise, articulate and critique the current situation and identify the kind of responses it wishes to see in place" (2003, p.3).

A large majority of the participants identified that there is a relationship between the destruction of the environment and health of the people. Some of them were able to identify it based on their working experiences. Although everybody agreed that there is a relationship between the destruction of the environment and health of the people, a small portion agreed on the role of social workers to advocate in this matter. Two out of eight interviewees claimed that environmental issues are important to them only at a personal level. But four out of eight indicated that historically, the social work profession is based on working for social justice, therefore, it is time to also include environmental justice in 
our professional concerns. It was interesting to find out that the majority of interviewees, five out of eight, believe that they have a responsibility to be aware of what is going on locally, nationally, and internationally.

A majority of the participants indicated that the state of the environment is in total crisis. There was not even one person who disagreed on this point. There were two results from these questions: shallow ecology and deep ecology. Those whose awareness fell into shallow ecology were not able to go beyond the dichotomy between human and nonhuman nature. They avoided fundamental questions about human values and lifestyles which have created this crisis. A slightly lower proportion, three out of eight, was able to move beyond shallow ecology and have a more holistic view of the problems.

The result indicates that some interviewees have awareness of the physical environment. Some talked about the responsibility of social workers in terms of justice. Some felt that they have responsibility towards local issues; for others it was local issues as well as global issues.

The responses varied from spending time in nature, to promoting more appreciation for it, to promoting environmentally-friendly practices in the work place and our living spaces. Some suggested that schools of social work offer courses to increase awareness of students in this matter.

\section{THE IMPLICATIONS OF DEEP ECOLOGY FOR SOCIAL WORK PRACTICE}

The social work profession has included the 'person in the environment' or structures in their practice for decades. However, this person/environment or structures 
has been narrowly defined as it excluded the natural environment in the definition. The major difficulty with much of social work's primary conceptual sources is the tendency to restrict the definition of environment to limited interpersonal realms (Besthron, 2001, 2002; Coates, 2003; Hoff, 1998). Some social work academics (Besthron, 1997; Hoff \& McNutt, 1994) were the first in the field of social work to expand the definition of the person and environment and to also include the physical environment in their definition. They were the first who began to address "the implications of nature's degradation and to explore its transcendent and spiritual value for informing social work theory and practice."

Even when the profession accepted the natural environment, it was shallow ecology; separating humans from the natural environment and something outside social work activity. The above theorists introduced the concept of deep ecology; that humans are related, dependent and also emerged from the natural environment (Besthorn, 2003, p.3). Therefore, by destroying the environment, we are destroying ourselves. Hoff \& McNutt (1994) captured this perspective with the following statement: "We destroy ourselves, our irreplaceable source of sheer physical substances, as well as the source of our imaginative capacities for expressing the penultimate realties of good, the true, and beautiful" (p. 50).

This exploratory study suggests that it is time to incorporate environmental issues into the curriculum of schools of social work. This study confirms that the social work profession has the theory and skills to respond to the new challenges that are facing humans as well as non-humans. This study confirms that the social work profession can make a change at the individual as well as collective level by incorporating deep ecology 
into its practice. Experts in the field of social work who have advocated at length for the relationship between the profession and the environment suggest the following areas in which the profession can have an impact: research, community organizing, social justice, direct practice, social policy, and international solidarity (Besthron, 2007, 2004, 2003, 2002; Calma, 2008; Camacho, 1998; Coates, 2003, 2005; Hare, 2004, 2008; Hoof, 1993; Ife, 2002, 2003, 2007; Lysack, 2007).

\section{Research}

Social work intervention has been expanded over the past decades. The profession has been involved in every social problem from child abuse to poverty, from violence against women to elderly problems, homelessness, young offenders, housing, and refugees, just to name a few. We are working within an environment which is constantly changing and constantly facing new challenges. One hundred years ago, there was some homogeneity of problems. However, with globalization, we are forced to get involved in new challenges and new demands. Today, we are required as humans and as professionals to come out of our cocoons, because macro and micro aspects are deeply linked due to globalization and the market economy. The social work profession can and should expand its skills and research on destruction of the environment and its effects on the people with whom we are working. "Social work researchers in health care are particularly challenged to assess the potential environmental linkage to developmental disabilities, cancer, and other diseases"(Hoff \& Polack, 1993, p.208). Social work can bring a unique point of view to the already rich source of data presented by environmentalists in the past twenty years (Hoff \& Polack, p.208). 


\section{Direct Practice}

Social work skills and its humanistic philosophy give an opportunity to help individuals and families look at their values and lifestyles which may bring misery to their lives, explain to our clients the difference between "to be" and "to have." These days, we don't need to be experts to determine that "to have" is our "collective voices of mindless consumerism" (Schumaker, 2002, p.34), which is human motivation. Social workers can explore the relationship between lifestyle and personal satisfaction in individual and group therapy. "The current widespread interest in addictive behaviors presents an opportune point of linkage to environmental concerns" (Hoff \& Polack, 1993, p.209). Studies show that high degrees of materialism have a toxic effect on psychological and social well-being. "A strong materialist orientation has been associated with diminished life satisfaction, impaired self-esteem, dissatisfaction with friendships and leisure activities, and a predisposition to depression" (Schumaker, p.35). The same writer indicates that escalating materialism may be the single largest contributor to Western society's tenfold increase in major depression over the past century, something that experts call "Consumption Disorders" (p.35). When materialism becomes the philosophy of existence, it is hard 'to be' and enjoy life and to be alive. Surveys of therapists reveal that 40 percent of Americans seeking psychotherapy today suffer from what is called "existential disorders" such as chronic boredom, meaninglessness, and alienation (Schumaker, p.35). The relationship between degradation of the urban environment and its effects on human well-being is not something which is new to the social work profession. "Founders of the profession, such 
as Jane Addams and Florence Kelly, recognized and sought to intervene in the deleterious human effects of degraded urban environments" (Hoff \& Polack, 1993, p.206). The profession also recognizes the relationship between wilderness experiences as therapy for delinquent or disturbed adolescents (Besthron \& Saleebey, 2003, 2001; Hoof \& Polack, 1993).

In my personal practice, the majority of the women I work with have depression. One of the suggestions that I make is to form a connection with nature. For example, getting involved in a community garden or, especially with the elderly, have a pet. Studies show that contact with nature has a positive effect on our emotions especially when we are under stress (Besthron, 2003, p.9). Therefore, appreciation of nature and its healing effects can be incorporated into the profession.

\section{Social Policy}

As previously indicated, a sustainable relationship with nature and our physical environment is necessary for the well-being of humans. Social workers who are engaged in the social policy area can seek specific policies which protect both humans and their physical environment. As Hoff reveals: "Environmental and human protection go hand in hand. Social questions of workplace safety, consumer protection, and health care costs all carry strong environmental elements" (p.209). Social welfare policy practitioners have a strong case to address environmental protection.

\section{Community Organizing}

Social workers have knowledge and skill in the area of community organizing. They can also empower people to represent their interest and take action. What is 
important is that the community members be involved in every step. Social workers can use their skills to network and establish relationships with a variety of people both inside and outside the community to effect change. Social workers have a long history of community work and facilitating the process of people defending their needs and interests, as well as negotiating obstacles. Social worker have unique skills of listening, empowerment, advocacy, networking, and research that can be "creatively applied to draw environmental groups into such causes as working against racism or reducing inner-city infant mortality rates" (Hoff \& Polack, 1993, p.208). Social work skills in organizing and community work could aid community groups in fighting the dangers of toxic products or other environmental threats (Bullard, 1990).

\section{Social Justice}

The social work profession has a long history of promoting social justice and human rights (Lundy, 2004, p.60). In 2002, the National Association of Social Workers indicated that human rights are a foundation principal of social work theory and practice (Lundy, p.69). Social workers have first hand experiences dealing with people whose basic social justices are violated. Social workers, with their knowledge and expertise in both direct and indirect services, can help individuals or groups by informing them of their rights, making them aware of resources available to help them, and challenging policies and procedures which affect their lives. The emphasis on advocacy, equality, and social justice is "grounded in a long tradition within social work of advocating for social justice, is on empowerment and social change. While it is within a radical tradition, it is also in keeping with the profession's code of ethics" (Lundy, 2004, p.67). Social workers 
have an opportunity to also advocate for social justice for future generations (Hoff \& Polack, 1993, p.208).

\section{International Solidarity}

In the age of globalization, the work of social workers has been affected by international issues. "As we move towards the new millennium, massive change is taking place around the globe. This change provides opportunities as well as challenges for social work's role and functions both nationally and internationally" (Hokenstad \& Midgley, 1998, p.1). In October 2007, at the Council for Social Work Education in San Francisco, Professor Jim Ife indicated that: "In this globalised and interconnected world, social work cannot help but be international if it is to continue to address the issues of social justice, inequality, oppression, exclusion, poverty and human rights abuse" (p.1). As social workers, we cannot afford to isolate ourselves just to the local environment. In the past century, social workers played a big role in addressing social injustices such as poverty, discrimination, and abuse, to name a few. With the new millennium, environmental issues have been added to the agenda. Ife revealed:

Global warming represents a far more serious and long lasting threat to the world, and the lives of all of us, than terrorism, and we can only wish that governments would spend as much time, effort and resources on counting the impacts of global warming as they do on fighting the so-called war on terror" (p.5).

As social workers, we have moral and ethical obligations to speak up about the effects of destruction of the environment on people's lives. Experts predict that there will be 
millions of climate refugees in the future (Ife, 2007; Mupedziswa, 1998). All these new challenges will have an impact on the social work profession. Experts indicate that:

Climate change will increasingly affect attempts by social workers to work internationally, as it will become another generator of social and economic inequality and injustice, and climate refugees will become a major social work concern. Social workers need to understand how it affects the populations they work with in different parts of the world, and should be engaged in the debate about climate change, arguing forcefully for the importance of social justice and human rights being at the forefront of policies designed to cope with and ameliorate global warming (Ife, p.9).

Social work has the skill and knowledge to address this new global threat like other problems and crises, and proudly, as Ife said, rediscover our profession's commitment. In this globalized world, "all social work is now international social work" (Ife, p.24). An Arab poet, Ahmad al-Mushari al-Udwani, explained this spirit of international social work in his beautiful poem called An Answer:

The stranger asked me what my country was

My country knows no exile, no "abroad"

I told her: My country is anywhere I meet

A stranger I can share friendship and love with

My country is an idea flowing with light

It is not bound to a flag or a piece of earth

I've left behind the tranquil motherlands

To those grown used to a settled life 
I've raced the winds on every horizon

The winds and I have sworn companionship

The social work profession has the opportunity to participate in sustainable development. The profession can use its firsthand experiences, knowledge, and skills to be involved in research, advocacy, community organizing, policy making, and direct counselling with people to play a vital role in this life threatening matter. In Hawaii, public policy requires social impact assessments for all development proposals, and social work practitioners have demonstrated their skills in conducting such analyses (Hoff, 1998, p.40). Assault on the environment has human dimensions such as poverty, displacement, unemployment, racial injustice, and health issues, even on future generations. All these problems demand the concern and commitment of social workers. As Hoff revealed: "Social work has both a challenge and an opportunity to transform its approach to practice and participate effectively in the development of an environmentally and socially sustainable community around the world" (1998, p.42). 


\section{CONCLUSIONS}

\section{Be the change you want to see in the world.}

\section{-Mahatma Gandhi}

Respect for nature and harmony with nature, slowly and painfully, is beginning to enter the consciousness of humans in the beginning of the $21^{\text {st }}$ century. Although the right of humans to a safe environment or "environmental human rights" belongs to the third generation of rights, it is not entirely new to political discourse. It has been talked about in many international agreements since 1972 . In 1972 , at the UN conference on the Human Environment in Stockholm, there were some initiatives taken to protect the environment. As indicated in the draft principles for a declaration on human rights and the environment, all persons have the right to freedom from pollution and activities that threaten life and health, and also have the right to safe and healthy food and water. Despite all of these efforts, the environmental crisis is reaching its peak. According to the UN (1994), the world supply of water per capita is only one third of what it was in 1970 . Six million hectares of land become desert each year. The rain forest is vanishing at an alarming rate. Almost six billion tons of carbon dioxide is released into the atmosphere every year. Rates of lung cancer, asthma, and other respiratory diseases are increasing each year. Human activities pose a serious threat to ecological systems. "Many modern stress-related diseases, as well as escalating levels of violence around the world, are traceable to the indifferent abuse of the environmental foundations of human life" (Hoff, 1998, p.31). In addition, environmental racism is the new face of racism in the $21^{\text {st }}$ century. 
All these developments are in opposition to the values of social work practice, which have focused on the elimination of all forms of social injustice. Social work is based on the respect, worth and dignity of people. Our focus is on poverty, discrimination, oppression and any forms of social injustice "When we do not respect the worth of the natural environment, we do not respect the worth and dignity of the people who reside in and depend on it" (Besthron, 2003, p.18). Now, with increasing public concern among social workers, as was demonstrated in this research, and a growing body of knowledge about the destruction of the environment and the health of our planet and people, social work education and practice needs to add a new environmental awareness to the profession's values and actions. "Social workers work with their clients on a variety of levels: the micro of individual and family; the meso level of community; and the macro level of society-nationally and internationally. Concern for human rights must be manifested by social workers at all levels and at all times" (Human Rights and Social Work, 1994, p.3).

We are living in a time of significant transition which changes the way we define human needs and human rights. Human rights do not just include the freedom to vote, the freedom of assembly, or free speech any more. The quality of the water we drink, the air we breathe, the food we put in our mouths, and the enjoyment and connection with nature are all part of human rights as well. As the global environmental crisis grows and our knowledge about the effects of this crisis on humans and non-humans increases, the world also shifts towards understanding our collective effort to deal with it. The social work profession has to adjust to this new reality. It is time to move out of the "cocoon" of our offices and start to see problems in a more holistic view if we want to be useful. The 
world is changing. One thing happens on one side of the world that will affect our lives the next day on the other side of the world. The profession of social work must adjust to the new reality of the new millennium. Therefore, it is better to prepare for this new reality.

The strength of the social work discipline has been its ability to see people in their particular environment. This environment has been viewed as family, community, friends, and other relationships. Now the profession has to expand its vision and its approach to also include the physical environment and the connection among all living entities. The profession needs to enrich itself by including not just the immediate social environment but also economics, politics, and ecology. The social work profession has the opportunity to participate in the sustainable development movement and to use its strength by helping people locally and internationally. It is time to abandon the idea of thinking globally and acting only locally. We need to think globally and act both locally and globally. Social workers can use their expertise and knowledge to help transform our society into one where people can live in harmony and dignity in relation to themselves and their environment. Social work practitioners can and should draw attention to the devastating effects of environmental destruction on the well-being of people, communities, and other species. "Social work has the choice of continuing to support a self- defeating social order or recreating itself to work towards a just and sustainable society" (Coates, 2000, p.159). It may be seen as something that does not belong to the profession of social work. When people found out that I was doing my thesis on the environment, they were surprised. They thought of the traditional role of social workers as working with abused women, foster children, poor people, those in the hospital, or 
with people who are physically and/or mentally different. Instead, it's time to make a connection between the environment and the well-being of humankind. After all, our responsibility as social workers is to support human well-being and that means improvement in the quality of life. Improvement in the quality of life means connections with other humans and all other beings. Quality of life means a decrease in consumption and an increase in connection.

Social work education can take small steps in this moral progress by raising social workers' consciousness about the global crisis and how it affects people and nature as a whole. The development of an understanding of social workers' current levels of awareness can be used to support further initiatives to deepen awareness for "ecologically responsible social work practice" (Besthron, 2002, p.81). Whether the profession and schools of social work are prepared to adjust to the new reality of the world, this research project is one small step towards this new vision.

As Einstein said:

A human being is a part of the whole, called by us "Universe" a part limited in time and space. He experiences himself, his thoughts and feelings as something separated from the rest - a kind of optical delusion of his consciousness. This delusion is a kind of prison for us, restricting us to our personal desires and affection for a few people physically near to us. Our task must be to free ourselves from this prison by widening our circle of compassion to embrace all living creatures and the all of nature in its beauty. Nobody is able to achieve this completely, but the striving for such achievement is in itself a part of the liberation, and a foundation for inner security. 


\section{REFERENCES}

Amnesty International (2009). Canada

Agarwal, B. (1996). Gender, environment, and poverty interlinks: Regional variations and temporal shifts in rural India, 1971-1991. Delhi, India: Institute of Economic Growth.

Agyeman, J. (2005). Sustainable Communities and the Challenge of Environmental Justice. New York: New York University Press.

AMNESTY International. (2009).

Ani, M. (1994). Yurugu: An African-Centered Critique of European Cultural Thought and Behavior. New Jersey: African World Press, Inc.

Badiner, A.H. (2002) (Ed). Mindfulness in the Marketplace: Compassionate Responses to Consumerism. Berkeley, California: Parallax Press.

Baechler, G. (1998). Environmental Change and Security Project Report. Issue 4, 24-44.

Baker, L. (2009). Feeling the Heat: Child Survival in a Changing Climate. Save the Children, $U K$.

BBC, Persian. (2007, 14 May).

Berger, R. \& Kelly, J. (1993). Social work in the ecological crisis. Social Work, 38(5), $521-526$

Berger, R. (1995). Habitat Destruction Syndrome. Social Work, 40 (4), 441-443

Besthron, F.H., Van Wormer, K., \& Keefe, T. (2007). Human Behavior and the Social Environment. Oxford University Press. 
Besthron, F.H. (2004). Restorative justice and environmental restoration-twin pillars of a just global environmental policy: Hearing the voice of the victim. Journal of Societal and Social Policy, 3(2), 33-48.

Besthron, F.H. (2003). Radical ecologisms: Insights for educating social workers in ecological activism and social justice. Critical Social Work: An Interdisciplinary Journal Dedicated to Social Justice, 3(1), 66-106.

Besthron, F.H., \& Saleebey, D. (2003). Nature, genetics and the biophilia connection: Exploring linkages with social work value and practice. Advances in Social Work, 4(1), $1-18$.

Besthron, H.F. \& Canda, E. (2002). Revisioning Environment: Deep Ecology for Education and Teaching in Social Work. Journal of Teaching in Social Work, 22(1/2), 79-101.

Besthron, F.H. (2002). Radical Environmentalism and the Ecological Self: Rethinking the Concept of Self-Identity for Social Work Practice. Journal of Progressive Human Services, 13(1), 53-72.

Besthron, F.H. (2001). Transpersonal Psychology and Deep Ecological Philosophy: Exploring Linkages and Applications for Social Work. The Haworth Press, Inc., 20(1/2), 23-44.

Biehl, J. (1991). FINDING OUR WAY::Rethinking Ecofeminist Politics. Montreal. Bleack Rose Books.

Borges, B. (2007). Poverty and Environment Partnership. Washington D.C.: InterAmerican Development Bank. 
Bookchin, M. (1995). Social anarchism or Lifestyle anarchism: the unbridgeable chasm. USA. AK Press.

Bookchin, M. (1987). Social Ecology Versus Deep Ecology: A Challenge for the Ecology Movement. Green Perspective.

Bookchin, M. (1980). Toward an Ecological Society. Montreal: Black Rose Books.

Braun, V., \& Clarke, V. (2006). Using thematic analysis in psychology. Qualitative Research in Psychology, Edward Arnold Ltd., 3, 77-101.

Brocklesb, M.A., \& Hinshelwood, E. (2001). Poverty and the Environment: What the Poor Say: An Assessment of Poverty-Environment Linkages in Participatory Poverty Assessments. Swansea: University of Wales, Centre for Development Studies.

Bullard, R. D. (2005). The Quest for Environmental Justice: Human Rights and the Politics of pollution. San Francisco: Sierra Club Book.

Bullard, R. D. (2000). Dumping in Dixie: Race, Class, and Environmental Quality. Colorado, U.S.: West view Press Inc.

Bullard, R. D. (1993). Anatomy of environmental racism and the environmental justice movement. In R.D. Bullard (Ed), Confronting environmental racism: voices from the grassroots (pp. 15-39). Boston: South End Press.

Bullard, R. D. (Ed). (1993). Unequal Protection: Environmental Justice and Communities of Color. San Francisco: Sierra Club.

Bulletin of the World Health Organization. (2000), 78 (9), 1-22.

Calma, T. (2008). the Role of Social Workers as Human Rights Workers with Indigenous People and Communities. Sydney: Australian Catholic University. 
Callicott, B. (1984). Non-Anthropocentric Value Theory and Environmental Ethics. American Philosophical Quarterly, 12 (4).

Camacho, D. E. (1998). Environmental Injustice, Political Struggles: Race, Class, and the Environment. London: Duke University Press.

Checker, M. (2005). Polluted Promises: Environmental Racism and the Search for Justice in a Southern Town. New York: University Press.

Chossudovsky, M. (1998). Global Poverty in the Late 20 Century. Journal of International Affairs, 52 (1), 293-311.

Clarkson, T.W. (1993). Mercury major issues in environmental health. Environmental health perspective, 100, 31-34.

Coates, J. (2005). The Environmental Crisis: Implications for Social Work. Journal of Progressive Human Services, 16(1), 25-49.

Coates, J. (2003). Ecology and social work: Toward a New Paradigm. Halifax: Fernwood Publishing.

Donohoe, M. (2003). Causes and health consequences of environmental degradation and social injustice. Social Science \& Medicine, 56, 573-587.

Drengson, A., \& Inoue, Y. (Ed). (1995). Shifting Paradigms: From Technocrat to Planetary Person in the Deep Ecology Movement. Berkeley, CA: North Atlantic Books.

Duraiappah, A.K. (1998). Poverty and Environmental Degradation: A Review and Analysis of the Nexus. World Development, 26 (12), 2169-2179.

Fox, W. (1989). The Deep Ecology-Ecofeminism Debate and Its Parallels. Environmental Ethics, 11, 5-25. 
Gachuruzi, S.B. (1996). The Impact of Refugees on the Environment: The case of Rwandan Refugees in Kivu, Zaire. Refugee, 15(2), 24-26.

Germain, C.B. (1979). Social Work Practice: People \& Environments, an Ecological Perspective. New York: Columbia University Press

Gkisedtanamoogk (1993). ANOQCOU: Ceremony is Life itself. Nobleboro, U.S: Blackberry Books.

Grey, W. (1943). Anthropocentrism and deep ecology. Australasian Journal of Philosophy, 71(4).

Hare, I. (2004). Defining social work for the 21st century: the International Federation of Social Workers' revised definition of social work. International Social Work, 47(3), 407427.

Harris, R. (2001). POMPEII. England: Arrow Books.

Healy, L.M. (2008). International Social Work; Professional Action in an Interdependent World. New York: Oxford University Press.

Healy, L.M. (1995). Comparative and International Overview. In Watts, T.D. \& Elliott \& Mayadas, N. (Eds) International Handbook on Social Work Education (pp.421-40). Westport, CT: Greenwood Press.

Hick, S., Fook, J., \& Pozzuto, R. (2005). Social Work: A Critical Turn. Toronto: Thompson Educational Publishing, Inc.

Hokenstad, M.C., \& Midgley, J. (Eds.). (1998). Issues in International Social Work: Global Challenges for a New Century. Washington, DC: NASW Press. 
Hoof, M. (1998). Social Work, the Environment, and Sustainable Growth. In Hokenstad, M.C. \& Midgley, J. ((Eds). Issues in International Social Work: Global Challenges for a New Century (pp. 27-44). NASW Press. Washington, DC.

Hoof, M., \& Rogge, M. (1996). Everything That Rises Must Converge: Developing a Social Work Response to Environmental Injustice. Journal of Progressive Human Services, $7(1)$.

Hoof, M., \& McNutt, J. (1994). The global environmental crisis: Implication for Social Welfare \& Social Work. Brookfield, USA: Arebury.

Hoof, M., \& Polack, R. (1993). Social Dimensions of the Environmental Crisis: Challenges for Social Work. Social Work, 38(2), 121-240.

Ife, J. (2007). The new international agenda: what role for social work? San Francisco, U.S.: Council for Social Work Education.

Ife, J., Healy, Spratt, \& Solomon. (2005). Current understanding of critical social work. In Hick, Fook, and Pozzuto (Eds.), Social Work: A critical turn. Toronto: Thompson Education publishing.

Ife, J. (2004). Living and Learning Together: the role of human rights education in strengthening communities in New Zealand and the Pacific. New Zealand: NZ Human Rights Commission \& NZ National Commission for UNESCO.

Ife, J. (2003). Community Development and Human Rights. Sydney: Centre for Human Rights Education.

Ife, J. (2002). Community Development. Community base development in an age of globalization. New York: Cambridge University Press. 
Ife, J. (2001). Human Rights and Social Work: Towards Rights-Based Practice. New York: Cambridge University Press.

Ife, J. (2001). Local and global practice: Relocating social work as a human rights profession in the new global order. European journal of Social Work, 4(1), 5-15.

Ife, J. (2001). Integrating Local and Global Practice Using a Human Rights Framework. Montpellier, France: IASSW Conference.

Jensen, D. (2004). It's not so much the number of people that's the problem: the problem is that Earth can't sustain Western over consumption. CCPA 11(2).

Lundy, \& Wormer, K.V. (2007). Social and economic justice, human rights and peace: The challenges for social work in Canada and the USA. International Social Work, Sage publications, 50(6), 727-739.

Lundy, C. (2004). Social Work and Social Justice. Bradview Press. Canada.

Lufumpa, C.L. (2005). The Poverty-Environment Nexus in Africa. African Development Bank. UK: Blackwell Publishing Ltd.

Lysack, M. (2007). Family therapy, the ecological self and global warming. Context, 91 , 9-11.

Lysack, M. (2003). When the Sacred Shows through: Narratives and Reflecting Teams in Counselor Education. Sciences/Pastoral Sciences, 22(1), 115-146.

Mabogunje, A. (2002). Poverty and environmental degradation: challenges within the global economy. Environment, 44(1), 56-58.

Macy, J. (2007). World as Lover, World as Self. Berkeley: Parallax Press.

Macy, J. (1998). Coming Back to Life: Practices to Reconnect Our Lives, Our World.

Canada: New Society Publishers. 
Macy, J. (1988). Thinking Like a Mountain. Canada: New Society Publishers.

Madill, A., \& Gough, B. (2007). Qualitative Research and Its Place in Psychological Science. American Psychological Association, 13 (3), 254-271.

Marlow, C., \& Van Rooyen, C. (2001). How green is the environment in social work? International Social Work, Sage Publications, 44 (2), 241-254.

Mathews. (1990). Relating to nature: Deep ecology or ecofeminism? Trumpeter, 11(4), 159-166.

Meze-Hausken, E. (2000). Migration Caused by Climate Change: How Vulnerable Are People in Dry Land Area. Case Study in Northern Ethiopia. Migration and Adaptation Strategies for Global Change, Kluwer Academic Publishers, 5, 379-406.

McGregor, J. (1993). Refugees and the environment. In Geography and refugees (pp. 157-170). London: Bellhaven Press.

McMichael, A.J. (1993). Global Environmental Change and Human Population Health: A Conceptual and Scientific Challenge for Epidemiology. International Journal of Epidemiology, 22(1) 176-179.

Midgley, J. (2001). Issues in International Social Work: Resolving Critical Debates in the Profession. Journal of Social Work, 1(21), 21-35.

Mupedziswa, R. (1998). Social Work with Refugees. In M.C. Hokenstad \& J. Midgley (Eds). Issues in International Social Work: Global Challenges for a New Century (pp.110-124). Washington, D.C.: NASW Press.

Murdy, W. (1975). Anthropocentrism: A Modern Version. Science, 187.

Naess, J. (2001). The Deep Ecological Movement: Some Philosophical Aspects:

Environmental Philosophy: From Animal Rights to Radical Ecology. Prentice-Hall, Inc. 
Naess, J. (1995). The Shallow and the Deep, Long-Range Ecology Movement: A Summary. In A. Drengson \& Y. Inoue (Eds.) The Deep Ecology Movement: An Introductory Anthology. Berkeley, California: North Atlantic Books.

Park, Y., \& Miller, J. (2006). The Social Ecology of Hurricane Katrina: Re-Writing the Discourse of "Natural" Disasters. Smith College Studies in Social Work, 76 (3), $62-67$.

Pepper, D. (1993). Eco-Socialism: from deep ecology to social justice. New York: Routledge.

PeTA, (2008).Norfolk, VA.

Reichert, E. (2003). Social Work and Human Rights. New York: Columbia University Press.

Rogge, M.E., \& Darkwa, O.K. (1996). Poverty and the environment: an international perspective for social work. International Social work, Sage Publications, 39, 395-409.

Rogge, M.E. (1994). Environmental injustice: Social welfare and toxic waste. In M.D. Hoff \& j McNutt (Ends). The global environmental crisis: Implications for social welfare and social work, (pp. 53-74). Aldershot: Ashgate/Avebury Books.

Rotabi, K.S. (2007). Ecological Theory Origin from Natural to Social Science or Vice Versa? A Brief Conceptual History for Social Work. Advance in Social Work, 8(1).

Save the Children UK. (2009). Park Communications Ltd.

Schumaker, J. (2002). An economy built on over consumption cannot be sustained. $C C P A, 3(2)$.

Sessions, G. (1995). Arne Naess and the Union of Theory and Practice. In The Deep Ecology Movement: An Introductory Anthology. Berkeley, California: North Atlantic Books. 
Shiva, V. (2005). Earth Democracy: Justice, Sustainability, and Peace. Cambridge, Massachusetts: South End Press.

Shiva, V \& Mies, M. (1993). Ecofeminism. Fernwood Publications. Halifax, Canada.

The CCPA. (2008), 15(2).

The CCPA. (2006), 13 (6).

The CCPA. (2005), 11 (3)

Toronto Star (October 20.2010). Canada

Thompson, G. (1993). Ecocentric and anthropocentric attitudes toward the environment. Journal of Environmental Psychology, 14, Issue. 2.

United Nations High Commissioner for Refugees. (1993). The state of the world's refugees: the challenge of protection. New York: Penguin Books.

Ungar, M. (2003). Deep Ecology and the Roots of Resilience: The Importance of Setting in Outdoor Experienced-based Programming for At-risk Children. Critical Social Work, $4(1)$.

Ungar, M. (2002). A Deeper, More Social Ecological Social Work Practice. Halifax, CA: Dalhousie University.

United Nations Population Information Network. (1994). Population \& the Environment in Developing Countries. New York: Oxford University Press.

United Nations Development Programme. Human Development Report 1992. New York: Oxford University Press.

United Nations Centre for Human Settlements (Habitat), Task Manager, Human Settlements. (1994). Sustainable Human Settlement Development. New York: Oxford University Press. 
United Nations (1994). Human Rights \& Social Work: A Manual for Schools of Social Work \& the Social Work Profession. New York \& Geneva.

Weiss, B., \& Bellinger, D. (2006). Social Ecology of Children's Vulnerability to Environmental pollutants. Environmental Health Perspectives, 114 (10), 1479-1485.

Wronka, J. (2008). Human Rights and Social Justice: Social Action and Service for the Helping and Health Professions. Thousand Oaks, CA: Sage

Zimmerman, M (1990). Deep Ecology and Ecofeminism in Reweaving the World. San Francisco: Sierra Club. 


\section{APPENDIX A: LETTER OF INFORMATION}

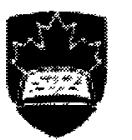

\section{Carleton \\ UNIVERSITY}

\section{Canada's Capilal University}

\section{School of Social Work}

1125 Colonel By Drive

Ottawa, Canada K1S 5B6

Tel: (613) 520-5601

Fax: (613) 520-74 96

\section{LETTER OF INFORMATION}

Manijeh Moghisi

MSW Student

Carleton University

School of Social Work

Ottawa, Ontario

Dear Participant:

Thank you for your interest in this project, which involves the collection of information to be used in my research project at the School of Social Work at Carleton University, Ottawa, Ontario. My research project, entitled "Social Work and The Environment," is being supervised by Professor Steven Hick of Carleton University's School of Social Work. The objective of this research project is to examine the opinions, awareness, and understanding of social workers concerning the extent of environmental destruction and of the environment's importance to the profession and to their personal approach to social work.

Your participation, which involves an in-depth one-on-one interview, will take approximately one hour of your time outside of your regular scheduled work hours. The location of the interview is your choice. It may be in your home or at a public place.

The following steps will be taken to protect your confidentiality. The names and contact information of participants will be kept separate (not with the rest of my thesis material), and only I will have access to this information. The data will be kept in a locked filing cabinet. Only my supervisor and I will have access, and all data will be destroyed after the research is complete, using a mechanical shredder. If you agree, I will use unattributed quotations from your interview and other interviews in the final report, maintaining the anonymity of the participants.

You may withdraw your agreement to participate at any time during the interview. At the time of your withdrawal, you may indicate whether or not the data collected up to that point may be used in study, and any information you do not give permission to use will be destroyed

To my knowledge, there are no known physical, social, economic, or psychological risks related to your participation in this project. However, some emotional issues may arise 
when you consider these issues. I am aware of this possibility and would encourage you to contact your EAP counsellor in case any issues arise. Your participation in this research is entirely voluntary. You are free to withdraw at any time from the project or to decide not to answer particular questions.

You can obtain a copy of the final findings by contacting me through my email address.

If you have any questions, concerns, or complaints about this project, please contact my supervisor, Professor Steven Hick (steven_hick @ Carleton.ca) at 613-520-2600, ext.

7499, or the Research Ethics Chair, Professor Antonio Gualtieri (ethics@carleton.ca), at 613-520-2517.

Thank you for your participation in the project

Sincerely,

Manijeh Moghisi 


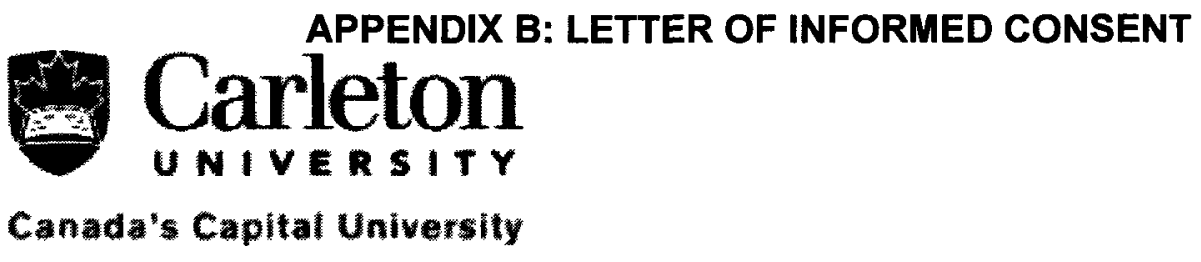

\section{School of Social Work}

1125 Colonel By Drive

Ottawa, Canada K1S 5B6

Tel: (613) 520-5601

Fax: (613) 520-7496

\section{RESEARCH STUDY: \\ SOCIAL WORK \& THE ENVIRONMENT}

\section{CONSENT FORM}

I understand that I have been invited to participate in a research study conducted by Manijeh Moghisi, who is a student enrolled in the Master of Social Work program at Carleton University. I have read the letter of information that has been provided by the researcher, and I understand that the information I provide will be used to complete the research project.

I understand that the purpose of this research study is to examine the opinions, awareness, and understanding of social workers concerning the condition of the environment and that condition's importance to the profession and to their personal approach to social work.

I understand that I may choose to provide information through an interview that will involve questions about my views of environmental matters and their relation to social work.

I understand that the interview will be recorded, and I give my permission to the researcher to record the interview.

I realize that the interview may take up to one hour to complete and that I may decline to answer any of the questions.

I understand that I may withdraw my agreement to participate at any time during the interview. At the time of my withdrawal, I may indicate whether or not the data collected up to that point can be used in the study, and any information I do not give permission to use will be destroyed.

I understand that it is possible others will know that I participated in this research project because my name has been provided by another participant.

I understand that I will not be identified in any report, but my comments may appear word-for-word. 
I understand that the notes and transcripts from the interview will be destroyed after the study is completed.

I understand that this project has been approved by the Carleton University Research Ethics Committee; if I have any questions or concerns I may contact the researcher, her supervisor, or the Ethics Committee chair.

Professor Antonio Gualtieri

The Research Ethics Chair

ethics@carleton.ca

613-520-2517

Professor Steven Hick

Research Study Supervisor

steven hick@Carleton.ca

613-520-2600 Ext. 7499

Manijeh Moghisi

mmoghisi@connect.carleton.ca

Signature of Participant

Date

Signature of Researcher

Date 